
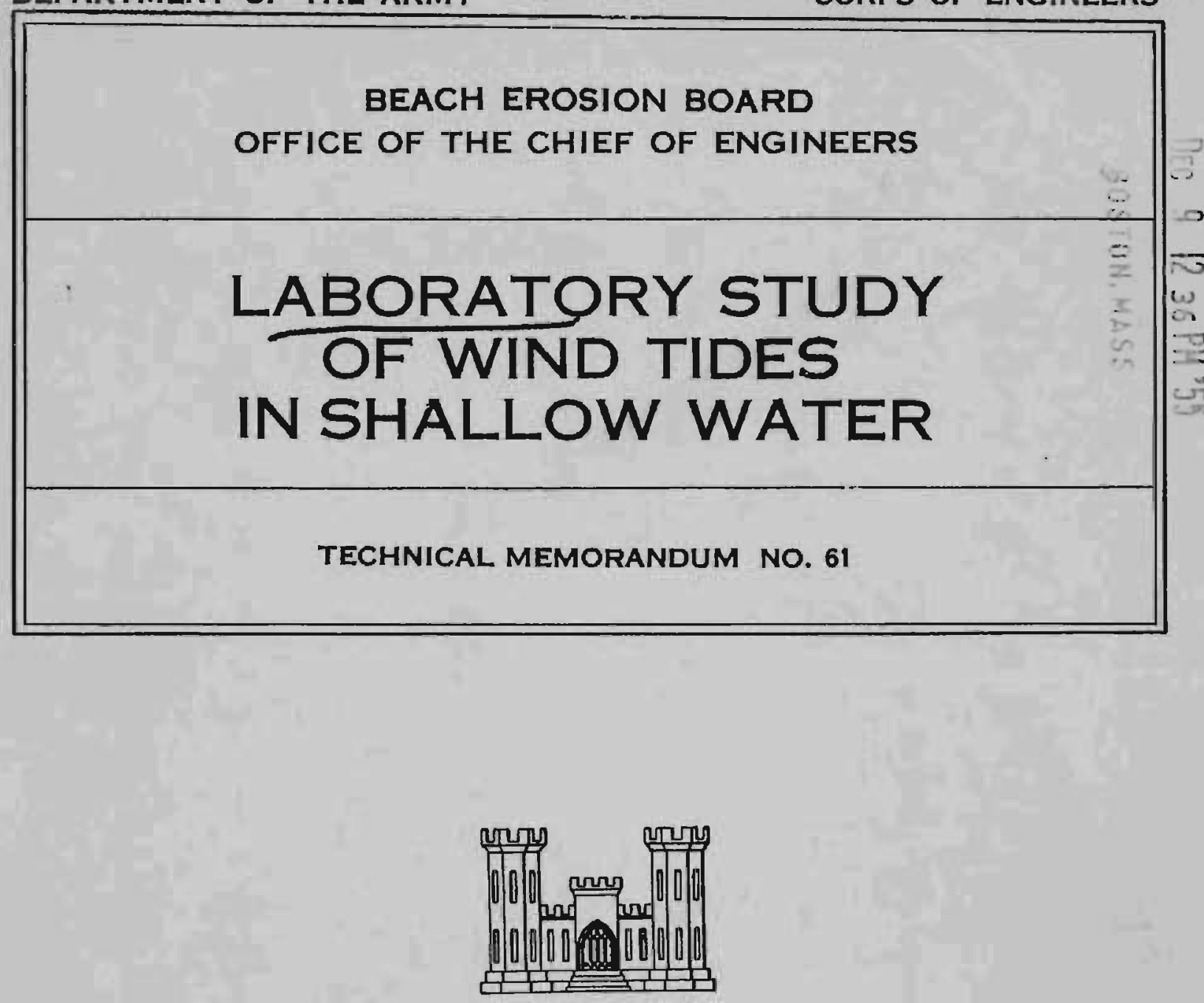


\section{LABORATORY STUDY OF WIND TIDES IN SHALLOW WATER}

TECHNICAL MEMORANDUM NO.61

BEACH EROSION BOARD CORPS OF ENGINEERS 


\section{FOREWORD}

When the wind blows over a water surface, in addition to generating waves it induces a surface current in the general direction of the wind movement; this results in a piling up of water at the leeward side of the water body and a lowering of water level at the windward side. This deviation from still-water level caused by the wind-driven currents, called wind set-up or wind tide, may reach significant proportions ( 9 and 10-foot rises in water level being not uncommon for Lake Okeechobee, Florida during hurricanes, for example) and represents a very important factor in shore protection design. Several methods of computing these set-ups have been derived, but all, of necessity, assume smooth bottom conditions; it is known, however, from observations at Lake Okeechobee and elsewhere that a rough bottom, or aquatic plants growing up through the water affect the set-up to a significant degree. These laboratory tests were made to enable some quantitative indication to be made of the importance of bottom effects and 1 ts dependence on such things as depth and wind strength. A considerable number of observations were made, and the data obtained should be of considerable interest to those involved in the design of structures where set-up over a rough bottom is important.

The empirical forecasting method given in the end of the report is but one possible method of obtaining set-up values and, while supported by the data presented in the report, does not appear to warrant preference over the more generally used step-integration methods given by Hellstrom, Keulegan, or Thijsse also discussed in the report and which have been successfully applied to a very large range of conditions in the fleld.

Views and conclusions stated in this report are not necessarily those of the Beach Erosion Board.

This report is published under authority of Public Law 166, 79th Congress, approved July 31, 1945. 
Page No.

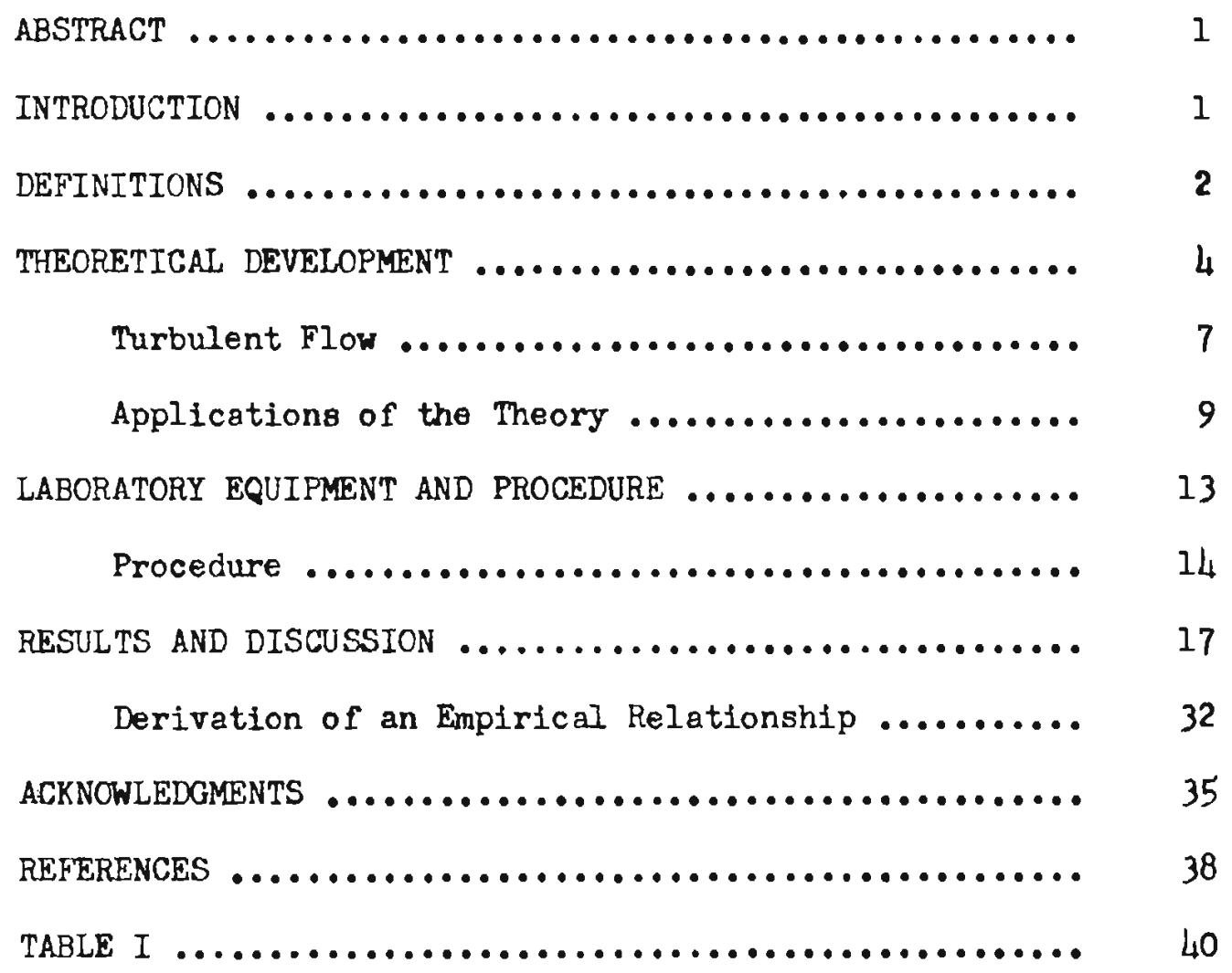




\author{
by \\ 0. Sibul \\ University of California \\ Berkeley, California
}

\begin{abstract}
Wind tides and wave conditions in shallow water were studied in a laboratory channel. The experiments were conducted with smooth and rough bottom conditions, and with strips of cheese cloth in the channel to simulate the roughness effects of vegetation in nature. The results indicate a rapidly increasing set-up when the still-water depth decreases below a certain limit. There were no indications that the bottom roughness affects the set-up for relatively deep water; in very shallow water, however, the rougher bottom conditions result in higher set-ups. The trend is especially pronounced for higher wind velocities. For the shallowest still-water depth $(0.05$ foot) used in the experiments, the set-up was approximately 10 percent higher for the rough bottom, and approximately 20 percent higher when strips of cheese cloth were used in the channel to simulate the roughness effect of vegetation, than the set-up observed with a smooth bottom.
\end{abstract}

\title{
INTRODUCTION
}

When wind is blowing over a water surface it generates waves, the heights and perlods of which are a function of wind intensity, wind duration, depth, and fetch. In addition to generating waves, the wind produces a tangential stress at the water surface with a resulting surface current in the general direction of the wind. In deep water, this current is balanced by the backflow in the lower layers. In shallow water, however, the backflow is affected by the roughness of the bottom and the water will "set-up" to the leeward until a sufficient pressure head is reached to balance the effect of bottom roughness. The more shallow the water, the more the bottom affects the backflow of water, and the higher the relative set-up must be to create an equilibrium condition between the wind generated current on the surface and the backflow along the bottom.

In limited bodies of water such as lakes, rivers, bays, and seas, wind tides have been measured and found to vary from a few inches for light winds to many feet in extreme cases involving hurricane winds over shallow bodies of water. Wind tides are capable of creating vast destruction when levees and dikes are not sufficient to withstand the combined action of wind tides and waves. For the proper design of shore protecting structures, the design engineer must be pble to predict the most critical condition for the given locality. The problem has been treated by numerous investigators theoretically as well as empirically. 
Wind tides and water surface slopes have been measured and analyzed in nature in the Baltic by Palmen 1 * and Palmen and Laurila2/, and in numerous inland lakes by Hellstrom $3 /$. The most complete data available for a large variety of conditions is the Lake Okeechobee data, obtained by the Corps of Engineers, U. S. Army 4 /. The latter data have been used by numerous investigators such as Hellstrom $3 /$, Langhaar 5/, Saville 6/, etc., to develop or verify various theories concerning wind tides.

Small scale laboratory investigations have been completed by Keulegan?,8/, Hellstrom $3 /$ and Francis9]. Dorn10/ has made a study in a large outdoor pond. Keulegan and Dorn, in their studies, demonstrated (by eliminating waves in some tests by the use of detergents) that two effects of the wind are involved: the surface traction of the wind, and the form resistance of the waves.

All of the laboratory investigations were completed, insofar as is known with a smooth bottom condition. For the natural bodies of water, however, the roughness of the bottom may have varied considerably; perhaps from being smooth sand on some occasions to being covered with dense vegetation on others. To study the effect of bottom roughness upon the characteristics of wind tides and the generation of waves, the experiments discussed below were completed using three different conditions of bottom roughness, i.e., a) smooth bottom, b) rough bottom, and c) rough bottom with strips of cheese cloth in the channel to simulate the effect of the roughness of vegetation in $n$ ture. Each of the conditions of roughness were combined with several depths of water.

\section{DEFINITIONS}

The definitions used in this report are shown in Figure 1.

A - the angle between the wind direction and tidal axis ( $A=0$ for the laboratory studies).

$B$ - a coefficient in Boussinesq's formula expressing the roughness of the boundary.

$F$ - the fetch in feet; the distance from the leeward still-water shore line to the point the set-up was measured.

$\mathrm{H}$ - wave height in feet.

I - the gradient of the flow (Chezy formula).

$K$ - a coefficient in Boussinesq's formula which depends upon the characteristics of the fluid.

$M$ - a coefficient depending upon the flow velocity (for low velocities $M=25$ ).

MII, the mean-water-level (see Figure 1).

$\mathrm{N}$ - the planform factor which takes the converging or diverging planform of the lake or channel into consideration.

$R$ - hydraulic radius in feet.

$S$ - the difference in windward and leeward water-surface elevations in feet, when the bottom at the windward end is not exposed.

* Numbers indicated by $/$ refer to references listed on page 38. 
$S^{\prime}$ - the elevation of the ML at the leeward shore above the horizontal bottom when the bottom at the windward end is exposed.

$S_{1}$ - set-up (difference in windward and leeward water surface elevations) due to the skin friction between wind and water surface.

$S_{2}$ - set-up (difference in windward and leeward water surface elevations) due to the form resistance of the waves.

$\mathrm{U}$ - the wind velocity in $\mathrm{ft} / \mathrm{sec}$.

$\mathrm{U}_{0}$ - the "formule characteristic velocity" in $\mathrm{ft} / \mathrm{sec}$. It is about 1.3 times the wind velocity necessary to start waves and was introduced by Keulegan ( 7 / and given as $14.4 \mathrm{ft} / \mathrm{sec}$. for the depth of 0.13 foot; $13.75 \mathrm{ft} / \mathrm{sec}$. for $\mathrm{d}=0.20 \mathrm{ft} . ; 12 . \mathrm{L} \mathrm{ft} / \mathrm{sec}$. for $d=0.26 \mathrm{ft}$; $11.8 \mathrm{ft} / \mathrm{sec}$. for $d=0.36 \mathrm{ft}$; and $11.5 \mathrm{ft} / \mathrm{sec}$. for $\mathrm{d}=0.475 \mathrm{ft}$.

SWL-the still-water-level; the surface of the water if all wave and wind action were to cease.

d - still-water depth in feet.

$\mathrm{g}$ - the acceleration of gravity $\left(32.17 \mathrm{ft} / \mathrm{sec}^{2}\right)$.

$h$ - the wind set-up above SWL in $\mathrm{ft}$. (the bottom at wincward shore not exposed).

$h^{\prime}$ - the wind set-up above SWL in $\mathrm{ft}$. (the bottom at windward shore is exposed).

$\mathbf{k}_{s}$ - equivalent sand roughness in feet.

$n$ - Manning's roughness coefficient.

$\mathrm{p}$ - pressure in $\mathrm{lbs} / \mathrm{ft}^{2}$.

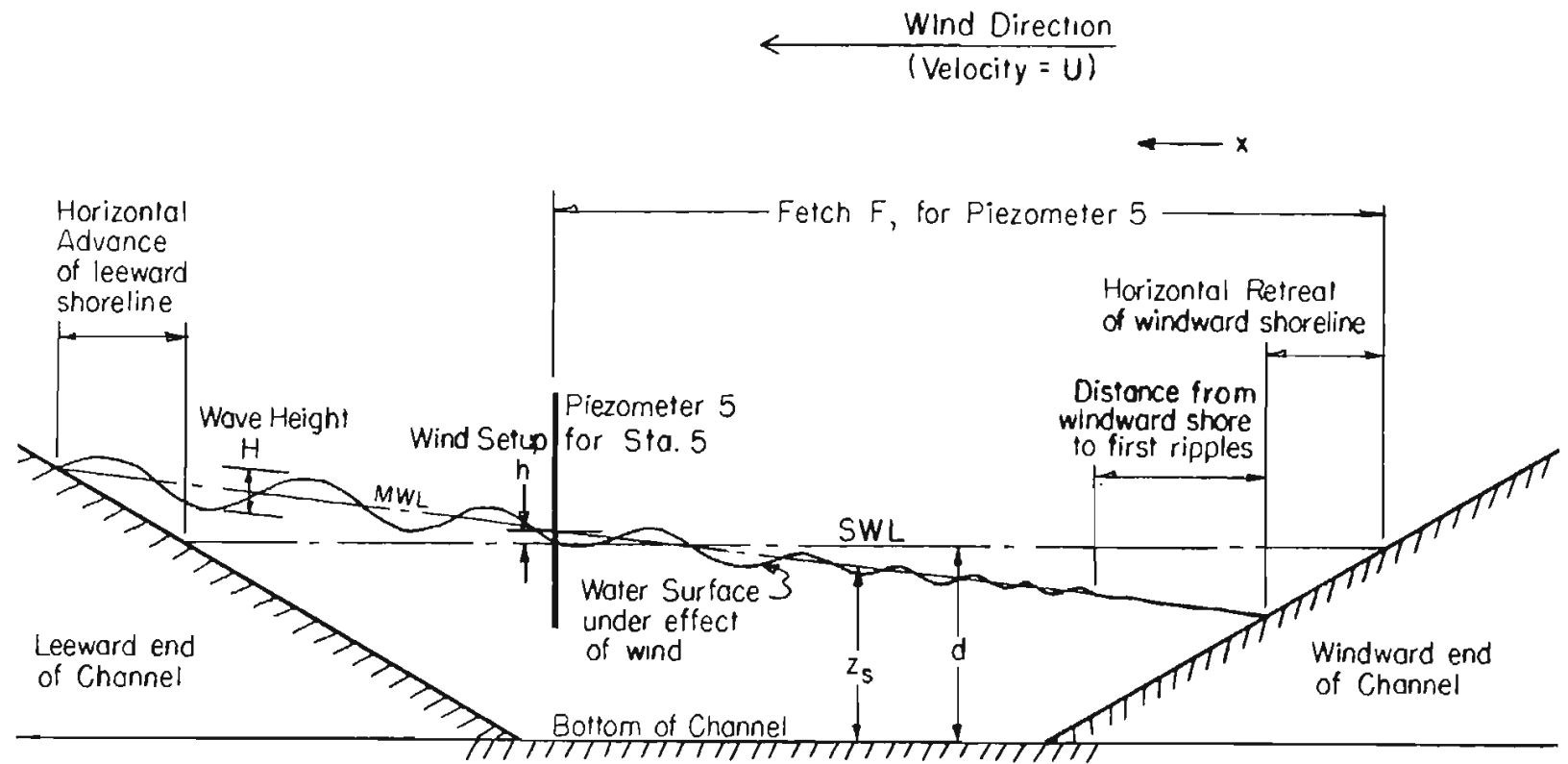

FIGURE 1 . 
$\mathrm{u}$ - wind velocity component in $x$-direction.

$u_{1}$ - velocity at the boundary in Boussinesq's equation.

$u_{s}$ - the velocity at the water surface.

$v$ - velocity component in y-direction.

$w$ - velocity component in $z$-direction.

$x$ - distance along $x$-axis.

$y$ - distance slong $y$-axis.

$\mathrm{z}$ - distance along $\mathrm{z}-\mathrm{axis}$.

$z_{s}$ - the distance from the bottom to ML.

$\gamma$ - unit weight of water.

$\epsilon$ - eddy viscosity.

$\lambda$ - a coefficient depending upon the turbulence in flow.

$\mu$ - coefficient of viscosity.

$\rho$ - density of the fluid.

$\tau_{b}$ - shear stress on the bottom.

$\tau_{s}-$ shear stress on the water surface.

\section{THEORETICAL DEVELOPMENT}

The analysis of wind tide data involves numerous variables which include the wind velocity and the energy transfer between the air and water, which in turn depend upon the wave conditions, temperature gradients, etc.i1). The depth and the geometrical shape of the body of water and the configuration and roughness of the bottom are other factors of importance. The stratiflcation (layers of different density) of water may influence the results considerably, and in very large bodies of water the rotation of the earth12,13,14/, and the variation of atmospheric pressure to the surface elevation and directions of currents may al so be important. To solve the problem theoretically, several assumptions must be made which include the flow conditions and viscosity at and near the air-water boundary. Several investigators have studied this problem using different approaches and assumptions. The most complete analysis so far available is that of Hellstrom 3/. In his treatment, he applied the Euler-Navier equation as given for the motion of a viscous incompressible fluid of a constant temperature, 1.e.,

$$
\begin{aligned}
& \rho\left(\frac{\partial u}{\partial t}+u \frac{\partial u}{\partial x}+v \frac{\partial u}{\partial y}+w \frac{\partial u}{\partial z}\right)=\rho X-\frac{\partial \rho}{\partial x}+\mu\left(\frac{\partial^{2} u}{\partial x^{2}}+\frac{\partial^{2} u}{\partial y^{2}}+\frac{\partial^{2} u}{\partial z^{2}}\right) \\
& \rho\left(\frac{\partial v}{\partial t}+u \frac{\partial v}{\partial x}+v \frac{\partial v}{\partial y}+w \frac{\partial v}{\partial z}\right)=\rho Y-\frac{\partial p}{\partial y}+\mu\left(\frac{\partial^{2} v}{\partial x^{2}}+\frac{\partial^{2} v}{\partial y^{2}}+\frac{\partial^{2} v}{\partial z^{2}}\right) \\
& \rho\left(\frac{\partial w}{\partial t}+u \frac{\partial w}{\partial x}+v \frac{\partial w}{\partial y}+w \frac{\partial w}{\partial z}\right)=\rho Z-\frac{\partial p}{\partial z}+\mu\left(\frac{\partial^{2} w}{\partial x^{2}}+\frac{\partial^{2} w}{\partial y^{2}}+\frac{\partial^{2} w}{\partial z^{2}}\right)
\end{aligned}
$$

and $\frac{\partial u}{\partial x}+\frac{\partial v}{\partial y}+\frac{\partial w}{\partial z}=0$.

Here $u, v$, and $w$ are the velocity components, parallel to the co-ordinate axes $x, y$, and $z$ at the time $t ; \rho$ is the density of fluid; $p$ the pressure; 
$\mu$ the coefficient of viscosity; and $X, Y$, and $Z$ the components of Coriolis' forces due to the rotation of the earth and gravity. Coriolis' forces act at right angles to the direction of the velocity, toward the right in the northern, and toward the left in the southern hemisphere. When $\omega$ denotes the angular velocity of the earth $\left(7.29 \times 10^{-5}\right)$, and $\zeta$ the latitude, then for the northern hemisphere $X=-2 v \omega \sin \zeta$, and $Y=2 u \omega \sin \zeta$. To solve Equation (1) the following assumptions are made: a) the flow is laminar, b) the depth is constant and small, c) the water surface slope is small, d) the pressure depends upon the depth below the surface only, e) the wind is constant, and $f$ ) the motion is steady and so the velocities are independent of time. Finally, the following expressions for the velocities $u$ and $v$ were obtained:

$$
\begin{aligned}
& u=\frac{\gamma}{\mu} \frac{\partial z_{s}}{\partial x}\left(\frac{z^{2}}{2}-z_{s} z\right)+\frac{\tau_{s}}{\mu} z \\
& v=\frac{\gamma}{\mu} \frac{\partial z_{s}}{\partial y}\left(\frac{z^{2}}{2}-z_{s} z\right) .
\end{aligned}
$$

For incompressible fluids:

$$
\int_{0}^{z_{s}} u d z=0 \text { and } \int_{0}^{z_{s}} v d z=0
$$

hence

$$
\frac{\partial \mathbf{z}_{s}}{\partial \mathbf{x}}-\frac{3}{2} \quad \frac{\tau_{s}}{\gamma_{\mathbf{z}_{\mathbf{s}}}}=0 \text { and } \frac{\partial \mathbf{z}_{s}}{\partial y}=0
$$

or, as $z_{g}$ is dependent on $x$ only,

$$
\frac{\partial \mathbf{z}_{\mathbf{s}}}{\partial \mathbf{x}}=\lambda \frac{\tau_{\mathbf{s}}}{\gamma \mathbf{z}_{\mathbf{s}}}
$$

where $\lambda=3 / 2$.

Equation (6) is the fundamental equation which is identical for the various investigators, regardless of the method of derivation, and is the basic formula for computing the wind effect. This formula demonstrates also that for lakes of shallow depth, the rotation of the earth has an insignificant effect on results. This is demonstrated also by the fact that Keulegan?/ arrived at the same results, although he neglected the effect of Corlolis' force in the original equation. According to Ekman12/, the rotation of earth will reduce the gradient of water surface in the ratio of 0.98 when the depth of water is 150 to 300 feet; in the ratio 0.77 when the depth is 400 to 750 feet; and by 0.66 when the depth is infinite. For Lake Geneva, Forel15] found that the direction of surface current in the water was the same as that of the wind direction, and that the return current along the bottom had a direction opposite to that of the surface current. This demonstrates that in lakes of reasonable 
size and depth, the rotation of the earth has a negligible effect on the direction of the currents.

A combination of Equations (2) and (3) with (5) gives the velocities $u$ and $v$ of the water particles, provided that laminar flow exists; 1.e.,

$$
\begin{aligned}
& u=\frac{3 \tau_{s}}{4 \mu z_{s}} z^{2}-\frac{\tau_{s}}{2 \mu} z \\
& v=0 .
\end{aligned}
$$

The velocity distribution curve in Equation (7) is parabolic with zero velocities at $z=0$ and $z=2 / 3 z_{8}$, and the maximum return velocity at $\mathbf{z}=1 / 3 \mathbf{z}_{5^{\circ}}$

The distribution of velocities may be studied also by dividing the total current into a drift-(caused by the wind) and a gradient-current (caused by the set-up). For the drift current, the water surface remaing horizontal and the pressure will be independent of $x$, so from Equation (I)

$$
\mu \frac{d^{2} u}{d z^{2}}=0
$$

On the other hand, for the gradient current the pressure depends upon the gradient $\frac{\partial p}{\partial x}=\gamma \frac{\partial z_{B}}{\partial x}$ and Equation (l) gives

$$
\mu \frac{\partial^{2} u}{\partial z^{2}}=\gamma \frac{\partial z_{s}}{\partial x}
$$

for the gradient current. The solution of Equations (9) and (10) gives

$$
u=\frac{\tau_{s}}{\mu} \quad z_{s}
$$

for the drift current, and

$$
\mathbf{u}=\frac{\gamma}{\mu} \frac{\partial \mathbf{z}_{s}}{\partial \mathbf{x}} \quad\left(\frac{\mathbf{z}^{2}}{2}-z_{s} \mathbf{z}\right)
$$

for the gradient current. The mean velocity for the gradient current can be found by integrating Equation (12) between $z=0$ and $z=z_{s}$, as

$$
u_{m}=-\frac{1}{3} \frac{\gamma}{\mu} \frac{\partial z_{s}}{\partial x} \quad z_{s}^{2}
$$

According to Equation (13), the mean velocity of the gradient current is directly proportional to the gradient $\frac{\partial z_{s}}{\partial x}$ of the water surface. For turbulent flow, however, the mean velocity is proportional to the square root of the gradient as demonstrated by the Che zy formula. 
The combination of Equations (11) and (12) gives the total velocity distribution, and is identical to Equetion (2).

The same results as given by Equations (2), (6) and (7) can be obtained by considering the state of equilibrium of acting forces as demonstrated by Hellstrom $3 /$ and 11 lustrated in Figure 2. The equations were established by:

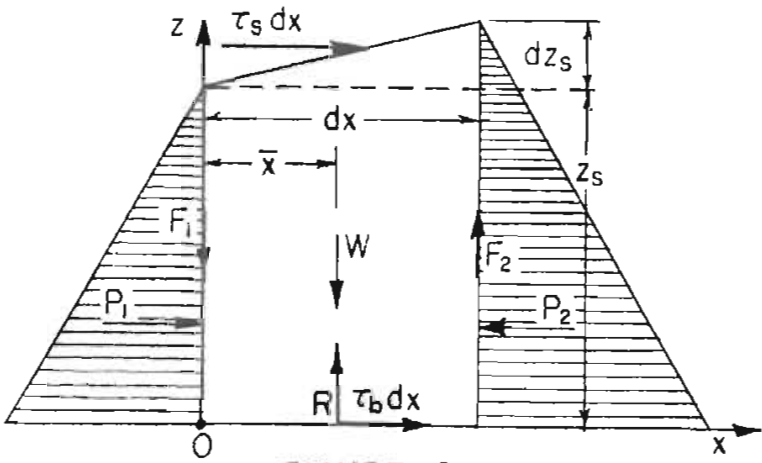

FIGURE 2 .

(a) taking the sum of forces in $x$ direction.

(b) taking the sum of forces in $y$ direction.

(c) taking the moments around point 0 .

In Figure 2, $P_{1}$ and $P_{2}$ are the total pressure forces, and $F_{1}$ and $F_{2}$ the total shear forces on the sides of element $d x$, which can be computed for a viscous incompressible fluid of constant temperature according to the laws of hydrodynamics. $\tau_{8} \mathrm{dx}$ is the wind force on the free surface, and $\tau_{b} d x$ is the frictional force

at the bottom. The resultant solution from this force balance is:

$$
-\frac{\mathrm{d} \mathrm{z}_{\mathrm{s}}}{\mathrm{dx}} \frac{2 \tau_{\mathrm{s}}}{\gamma_{\mathrm{z}_{\mathrm{s}}}}-2 \mu \frac{\mathrm{u}_{\mathrm{s}}}{\gamma_{\mathrm{z}_{s}{ }^{2}}}
$$

Equation ( 14 ) demonstrates that the total gradient regults from a combination of static-(first term) and flow-(second term) conditions. By replacing $u_{s}$ (water surface velocity) in Equation (14) with an expression as found from Equation (7) for $z=z_{5}$, we obtain an equation identical to Equation (6).

Summarizing the findings for laminar flow, the equation for the watersurface gradient for limited bodies of water of reasonable depth is defined by Equation (6), and the frictional force per square unit at the bottom, $\tau_{b}$, is half the value of the wind drag force, $\tau_{s}$, on the surface. The coefficient, $\lambda$, in Equation (6) is equal to $3 / 2$ for laminar flow.

\section{Turbulent Flow}

Equation (6) was derived without consideration of turbulence, which exists in practically all important cases. Equation (13) demonstrates, as mentioned previously, that the mean velocity, $u_{m}$, caused by the set-up of the leeward end is directly proportional to the water surface gradient $\frac{\partial z_{8}}{\partial x}$. Chezy, however, established in 1775 the empirical formula for turbulent flow ( $u_{m}=c \sqrt{R I}$ ) where the mean velocity is proportional to the square root of the gradient. Application of Equation (13) for turbulent flow gives values which are far too high. Any attempt to apply the theories 
of laminar flow to turbulent flow will encounter the assumption that the coefficient of viscosity is constant and independent of the velocity. It is very difficult to establish average values for they vary with the flow condition throughout the fluid.

According to Boussinesq16,17,18/, turbulent motion can be expressed by Equation ( 1 ) when, instead of a constant coefficient of viscosity, $\mu$, a coefficient $\epsilon$ is introduced which depends upon the nature of lluid as well as upon the flow condition. is usually called the eddy viscosity. Boussinesq puts

$$
\epsilon=\frac{\rho g}{K} \sqrt{B}{ }^{2}{ }_{s} u_{1}
$$

where $K$ is a coefficient depending upon the characteristics of lluid, $B$ expresses the roughness of the boundary, and $u_{1}$ is the velocity at the boundary. Hellstrom 3 , by determining $u_{1}$, obtains

$$
\epsilon=\frac{z_{B} \sqrt{y}}{\pi} \sqrt{\gamma \frac{d z_{s}}{d x} z_{s}-\tau_{s}}
$$

Rewriting the first part of Equation (1), then

$\rho\left(\frac{\partial u}{\partial t}+u \frac{\partial u}{\partial x}+v \frac{\partial u}{\partial y}+w \frac{\partial u}{\partial z}\right)=\rho x-\frac{\partial p}{\partial x}+\left[\frac{\partial}{\partial x}\left(\epsilon \frac{\partial u}{\partial x}\right)+\frac{\partial}{\partial y}\left(\epsilon \frac{\partial u}{\partial y}\right)+\frac{\partial}{\partial z}\left(\epsilon \frac{\partial u}{\partial z}\right)\right]$

The rest of Equation (1) can be modified in an analogous manner. Asauring now that the coefficient of turbulence can be expressed through Equation (15), and that the frictional force at the bottom is equal to

$$
\tau_{b}=\rho g B u_{1}^{2}
$$

the velocity distribution $K$ obtained as

$$
\begin{aligned}
& u=\frac{\mathrm{k} \sqrt{y}}{z_{s} \sqrt{\gamma \frac{d z_{s}}{d x} z_{s}-\tau_{s}}} \frac{d z_{s}}{d x} \frac{z^{2}}{2} \\
& -\frac{k}{z_{s_{v} / \gamma} \sqrt{\gamma-\frac{d z_{s}}{d x} z_{s}-\tau_{s}}}\left(\gamma \frac{d z_{s}}{d x} z_{s}-\tau_{s}\right) z-\sqrt{\frac{\gamma \frac{d z_{s}}{d x}-\tau_{s}}{\sqrt{\gamma^{B}}}}
\end{aligned}
$$

And finally, integrating the velocity u over the entire depth,

$$
\frac{\mathrm{dz}^{\mathbf{z}}}{\mathrm{dx}}=\lambda \frac{\tau_{\underline{s}}}{\gamma \mathbf{z}_{\mathbf{s}}}
$$


Equation (19) has exactly the same form as found for laminar flow. The coefficient varies, however, depending upon the flow condition. Hellstrom gives

$$
\lambda=\frac{3}{2} \frac{(K-\sqrt{8}+2)}{(K \sqrt{B}+3)}
$$

When $K \sqrt{A} \longrightarrow \infty$, then $\lambda \rightarrow 3 / 2$; this case represents the laminar flow condition, and Equation (20) is identical with Equation (6). When $\mathrm{K} \sqrt{\mathrm{B}} \rightarrow 0, \lambda \rightarrow 1$; hence

$$
1 \leq \lambda \leq 1.5
$$

Boussinesq estimates for water, $K=45 \mathrm{~m} / \mathrm{sec}$. and

$$
B=\frac{9}{\left(3 \mathrm{MR}^{1} / 6^{-}-\mathrm{K}^{2}\right.}
$$

where $M=25$ for lakes where the velocity is low.

A combination of Equations (18) and (19) gives a different form of equation for the velocity $u$

$$
u=\frac{k \lambda \tau_{s}}{2 \sqrt{\gamma} \sqrt{\tau_{s}(\lambda-1)}}\left(\frac{z}{z_{s}}\right)^{2}-\frac{k \sqrt{\tau_{s}(\lambda-1)}}{\sqrt{\gamma}}\left(\frac{z}{z_{s}}\right)-\frac{\sqrt{\tau_{s}(\lambda-1)}}{\sqrt{\gamma B}}
$$

Equation 23 demonstrates that the velocity u is directly proportinnal to the square root of the wind force on the water surface, hence proportional to the wind velocity.

\section{Applications of the Theory}

Most investigators give the differential equation for the free water surface affected by a constant wind force in a form identical to Equation (19). The application of this equation to the computation of wind tides has various forms; that is,

1. Hellstrom integrates Equation (19) to get

$$
\mathrm{z}_{\mathrm{s}}{ }^{2}=\frac{2 \lambda \underline{\tau}_{\mathrm{B}}}{\gamma} \quad\left(\mathrm{x}+\mathrm{c}_{1}\right)
$$


a)

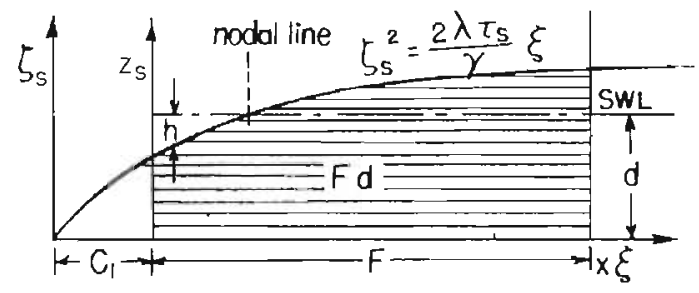

b)

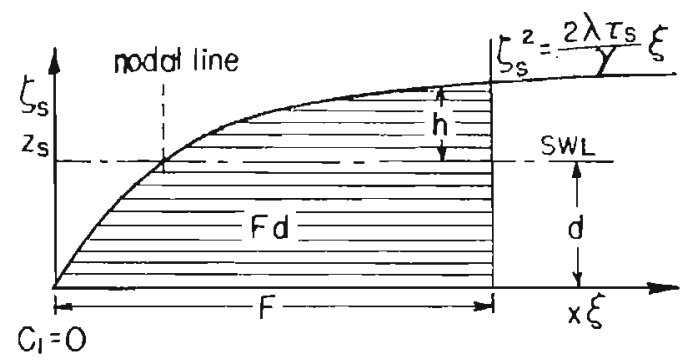

c)

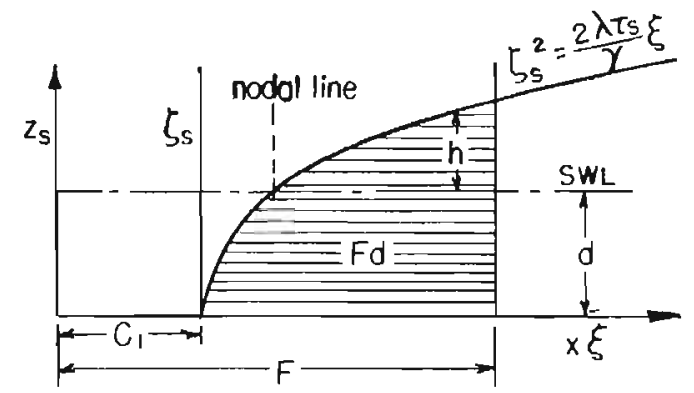

FIGURE 3 .
Equation (24) indicates that the water surface is parabolic in form and may be written in coordinates $\zeta$ and $\xi$ as follows:

$$
\zeta_{5}^{2}=\frac{2 \lambda \tau_{8}}{\gamma} \xi
$$

Equation (25) is plotted in Figure 3. Hellstrom calls Equation (25) the "Characteristic Water Surface Parabolan. The next step is to cut out a portion of the parabola in length $F$ so that the area between the curve and the $x$-axis is equa? to $F d$ (shaded area in Figure 3), where F is the length of the channel and $d$ the still-water depth. The so-found distance between the $z-$ and $\zeta-a x i s$ gives the constant $\mathrm{C}_{1}$ as indicated in Figure 3. The case where the bottom is not exposed is represented by Figure $3 a$, and $C_{1}$ is a positive value. Figure $3 b$ represents the case $G_{1}=0$, wherein the water surface at the beginning of the channel has the same elevation as the bottom. The case with an exposed bottom. is given in Figure $3 c$, and here $C_{1}$ is negative.

Finally, the set-up, h, can be computed from Equation (26)

$$
h=\sqrt{\frac{2 \lambda \tau s}{\gamma}\left(x+c_{1}\right)}-d \text {. }
$$

The nodal-line can be computed from Equation (26) for $h=0$. formula

When the depth is great as compared with set-up, Hellstrom gives the

$$
h=\frac{\lambda \tau_{s}}{\gamma d}\left(x-\frac{F}{2}\right)
$$

The nodal-Iine for (27) is at $x=F / 2$ and the set-up at the windward shore, $x=0$, is:

$$
\mathrm{h}_{\mathrm{x}}=0=\frac{\lambda \tau_{\mathbf{s}} \mathrm{F}}{2 \gamma \mathrm{d}}
$$

and at the leeward shore, $x=F$

$$
h_{x}=F=\frac{\lambda \tau_{s} F}{2 \gamma d}
$$


2. Langhaar's analysis $5 /$ is based on the momentum principle, separating the effect into statical and dynamical components. The statical tide is the tide that the wind would maintain if it persisted indefinitely; the tide due to the seiches is called the dynamical tide. He gives two different formulas for statical tides, depending upon the magnitude of the wind tides.

the formula:

(a) For omall tides where the bottom is not exposed he gives

$$
h_{x}=F=\frac{\tau_{B} F}{2 \gamma d}
$$

where $h_{x}=F$ indicates the wind tide above the original still-water at the leeward shore. The formula is identical to Equation (28a), as presented by Hellstrom for $\lambda=1$.

(b) For the cose where part of the windward bottom is exposed:

$$
s^{\prime}=\sqrt[3]{\frac{3 \tau s \mathrm{~d}}{\gamma}}
$$

$S^{\prime}$ in Equation (30) indicates the depth above the horizontal bottom, and at the leeward shore. The set-up above SWL is $\mathrm{h}^{\prime}=\mathrm{S}^{\prime}-\mathrm{d}$. Equation(30) determines the statical tide in any lake that does not have a pronounced taper of planform, provided that the wind is so strong that the bottom is exposed at the windward end. This equation indicates that the depth of water at the leeward end of the lake varles as the two-thirds power of the wind velocity and as the cube root of the length of the lake.

The Jacksonville District, Corps of Engineers, U. S. Armyl9/ have found numerous applications for Equation (30). During their investigation it was found necessary, however, to change a constant in this equation. They give the formula as

$$
h_{x=F}=\sqrt[3]{\frac{3.373 \tau_{s} F d N}{\gamma}}-d
$$

$h^{\prime}$ in this formula gives the set-up above SWL for the case when a portion of the windward bottom is exposed. N in Equation (31) is the so-called planform factor which takes into consideration the converging or divergIng planform of the lake or channel. For the case where the body of water has a constant width, the planform factor $N=1$. For a converging planform, $N>1$, and for a diverging planform $N<1$.

3. Keulegan?/ derives a differential equation for the water surface which is identical to that of Equation (19). He gives the definition for the coefficient $\lambda$ as:

$$
\lambda=\frac{\tau_{b}}{\tau_{s}}+1
$$


For purely viscous laninar flow, $\lambda=1.5$ and the equation takes an identical form with Equation (6). For turbulent flow Keulegan adopted temporarlly the value, $\lambda=1.25$.

In his experimental $s$ tudy, Keulegan separated the total set-up $S$ into two parts; (a) $S_{1}$, the set-up due to skin friction between wind and water surface; and (b) $s_{2}$, the set-up cue to the form resistance of the waves. S is defined as the difference between the water-surface elevations at the windward and the leeward ends of the channel.

$$
S=s_{1}+s_{2}
$$

The set-up without the wave action was found to be

$$
S_{1}=c_{2} \times 10^{-6} \frac{u^{2} F}{g d}
$$

and the set-up due to the waves,

$$
\mathrm{S}_{2}=\mathrm{C}_{3} \frac{\left(\mathrm{U}-\mathrm{U}_{0}\right)^{2} \mathrm{~F}}{\mathrm{~d}}\left(\frac{\mathrm{d}}{\mathrm{F}}\right)^{\frac{1}{2}}
$$

Keulegan gives further, $C_{2}=3.3 \times 10^{-6}$, and $C_{3}=2.08 \times 10^{-4}$, so the total set-up will be

$$
S=\left[3.3 \times 10^{-6} \frac{U^{2}}{g d}+2.08 \times 10^{-4} \frac{\left(U-U_{0}\right)^{2}}{g d}\left(\frac{d}{F}\right)^{\frac{1}{2}}\right] F
$$

$U_{0}$ is referred to by Keulegan as the "formula characteristic velocity", and is approximately 1.3 times the lowest wind velocity necessary to start waves. Keulegan determined $U_{0}$ as a function of water depth. The values given by him for $U_{0}$ are plotted in Figure 4 , and are connected by a curve. Equation (36) was established using small-scale laboratory experimerits.

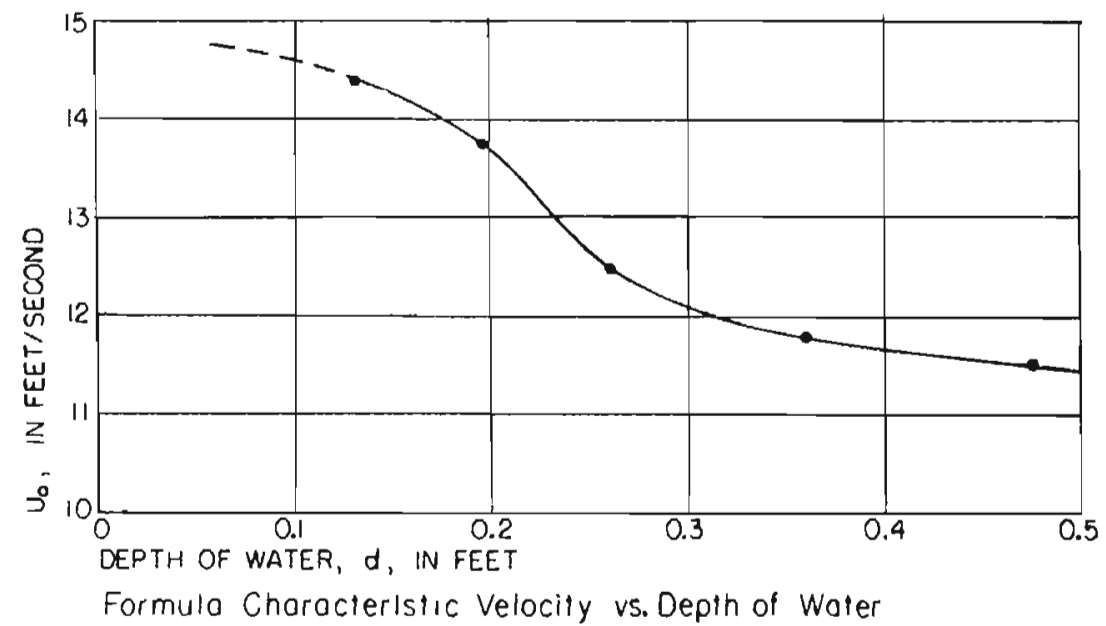

FIGURE 4. 
Keulegan states further that the critical wind velocity for the genesis of waves on a large body of water is about one third as great (somewhat more than $3 \mathrm{ft} / \mathrm{sec}$.) as the corresponding values obtained in laboratory channels, and so $U_{0}$ may be onfted in Equation (36) without causing a large error. The set-up formula for the large bodles of water is then given as:

$$
\mathbf{S}=3.3 \times 10^{-6}\left[1+63\left(\frac{\mathrm{d}}{\mathrm{F}}\right)^{\frac{3}{2}}\right] \frac{\mathrm{U}^{2} \mathrm{~F}}{\mathrm{gd}}
$$

and it applies when the body of water approxtmates the shape of a rectangular channel of unf form cross-section.

4. In addition to the above formulas for wind tides in shallow water, there are variety of other formulas which are generally identical in form but vary in the constants to be used. Among these the Zuider Zee formula should be mentioned. Originally the formul.a was given as:

$$
S=\frac{U^{2} F}{800} d
$$

where $S$ is again the difference in windward and leeward water-surface elevations, $U$ is the wind velocity in miles per hour, $F$ is the fetch in miles, and $\mathrm{d}$ the depth in feet. The formula (38) was later modified? to

$$
h=\frac{U^{2} F}{1400 d} \cos A
$$

Here $h$ is the set-up in feet above the original still-water elevation at the leeward end, $U$ is in miles per hour, $F$ is in miles, and $d$ is in feet. $A$ is the angle between the wind and tidal axis.

The Beach Erosion Board formula (6) was presented as:

$$
\mathrm{S}=\frac{\mathrm{k} \lambda \rho_{\mathrm{g}} \mathrm{U}^{2} \mathrm{~F}}{\rho \mathrm{g} \mathrm{d}} \cos \mathrm{A}
$$

$S$ represents here the difference in water-surface elevations at windward and leeward sides of the lake, $\rho 0$ is the air density, $k$ is a numerical constant approximately equal to $0.003, \lambda$ is as defined above in Equation (32) and $A$ denotes the angle between the wind and the fetch.

\section{LABORATORY EQUIPMENT AND PROCEDURE}

Experiments were performed in a channel 1 foot wide, 60 feet long and 1.28 feet deep, as shown in Figure 5a. The length of the channel was about 60 feet, essentially the same as that used by Keulegan?], but the width ( 1 foot) was approximately three times greater and the depth (1.25 feet) somewhat larger than that used by Keulegan (0.93 foot). The channel was constructed of wood, with one side made of plate-nglass for observational purposes. The wind was generated by a blower, mounted 
at one end of the channel, driven by an a.c. motor. The wind velocities could be varied from 0 to approximately $50 \mathrm{ft} / \mathrm{sec}$. by varying the air intake area at the blower. To straighten the wind flow upon entering the channel, a honeycomb was set between the blower and the channel. To guide the wind gradually on and off the water surface, a sloping beach (slope approximately $1: 15$ ) was set at the beginning and the end of the channel, as shown in Figure 5a. The downwind (leeward) beach served also as a wave absorber to reduce the effect of wave reflection. The discharge of air was measured by a Venturi meter mounted as shown in Figure 5a. The Venturi meter was used to obtain approximately the desired wind velocity. The final wind velocity measurements were made, however, by using Pitot tubes mounted on point gages.

Piezometer openings were installed on the top and the bottom of the channel at five locations along the certerline. The openings were connected to Piezometers, as shown in Figure $5 \mathrm{~b}$, so that both the water depth and the total pressure, above atmospheric, could be read directly. The difference between the two readings gave the inside air pressure, and the drop in pressure between successive piezometers was used to determine corrections to be applied to the measured water-surface profiles. To check the latter measurement, three draft gages were connected to the piezometer opening on the top of the channel at the locations of alcropiezometers 1,3 , and 5 as shown in Figure 5a, and the pressure readings were made simultaneously with those of the microplezometers. These two readings always agreed very closely. Any difference indicated a faulty connection or a clogging of the piezometer opening, and corrections were made at once.

The wave heights and periods were measured at four locations, as indicated in Figure $5 \mathrm{a}$, by the use of parallel-wire resistance elements connected to Brush recorders. A section of the channel is pictured in Figure 6. The photograph show:; a piezometer, pitot tube, draft-gage, and a wave gage with a brush recorder.

Procedure

The desired wind velocity was obtained by adjusting the air inlet or the blower to the proper size. The blower then was shut off and the ends of the channel were closed so that no air movement could occur in the channel and influence the inftial still-water elevation. When the water surface had calmed completely, the still-water elevation was determined at the location of each of the five piezometers. The blower then was started and the wind velocity profiles obtained at the three locations along the channel, as shown in Figure $5 \mathrm{a}$. In later tests, only the wind velocity profile at the middle of the channel was obtained. Aiter letting the blower run at least a half an hour, and when there was every indication that the flow condition had stabilized the surface profile was measured. Because of side wall friction and the energy transfer from wind to waves, the pressure in the channel drops gradually as the wind passes through the channel, and the measured water-surface profiles are 


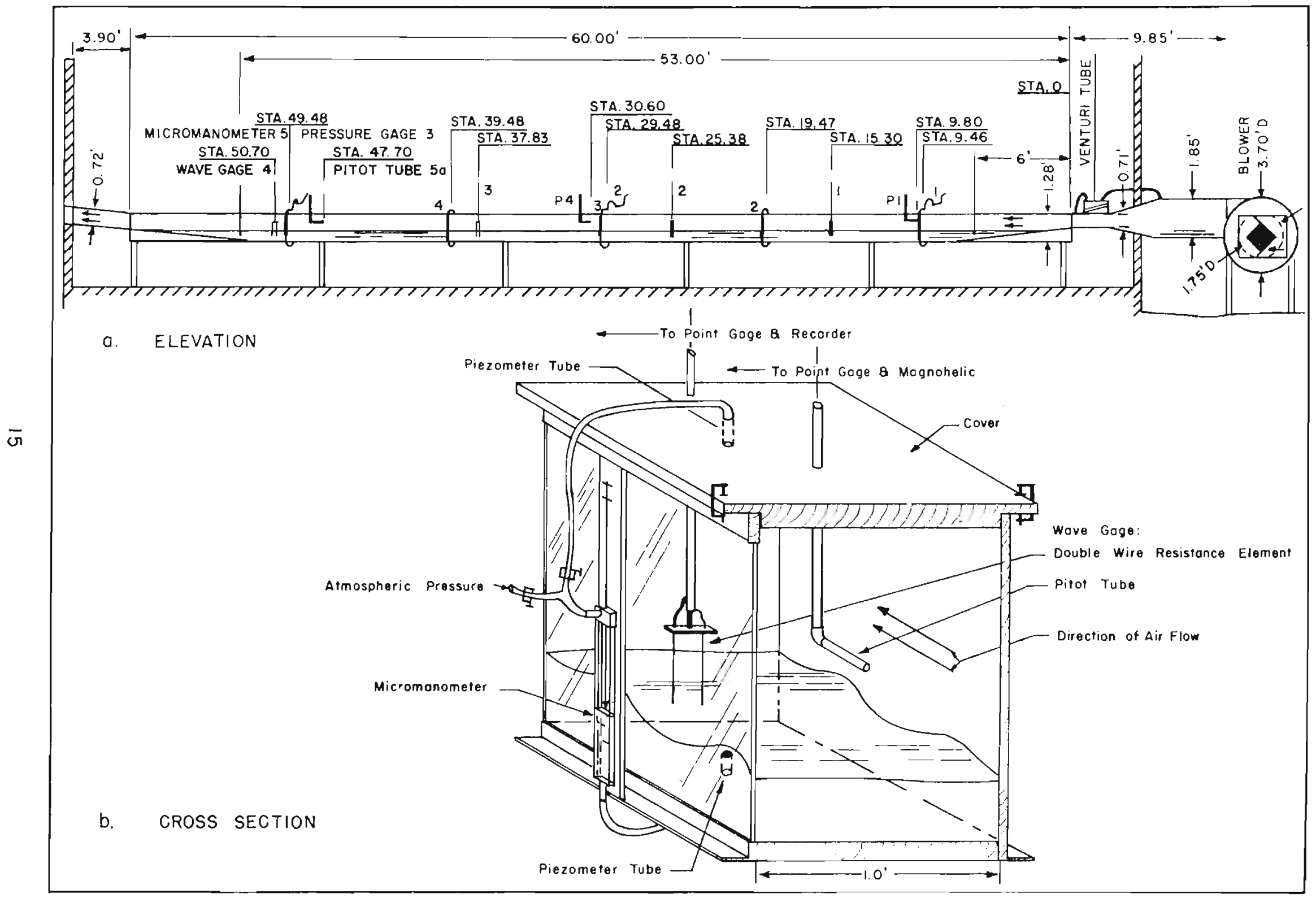

FIGURE 5 - GENERAL LABORATORY SET-UP FOR STUDY OF WIND TIDES IN SHALLOW WATER 


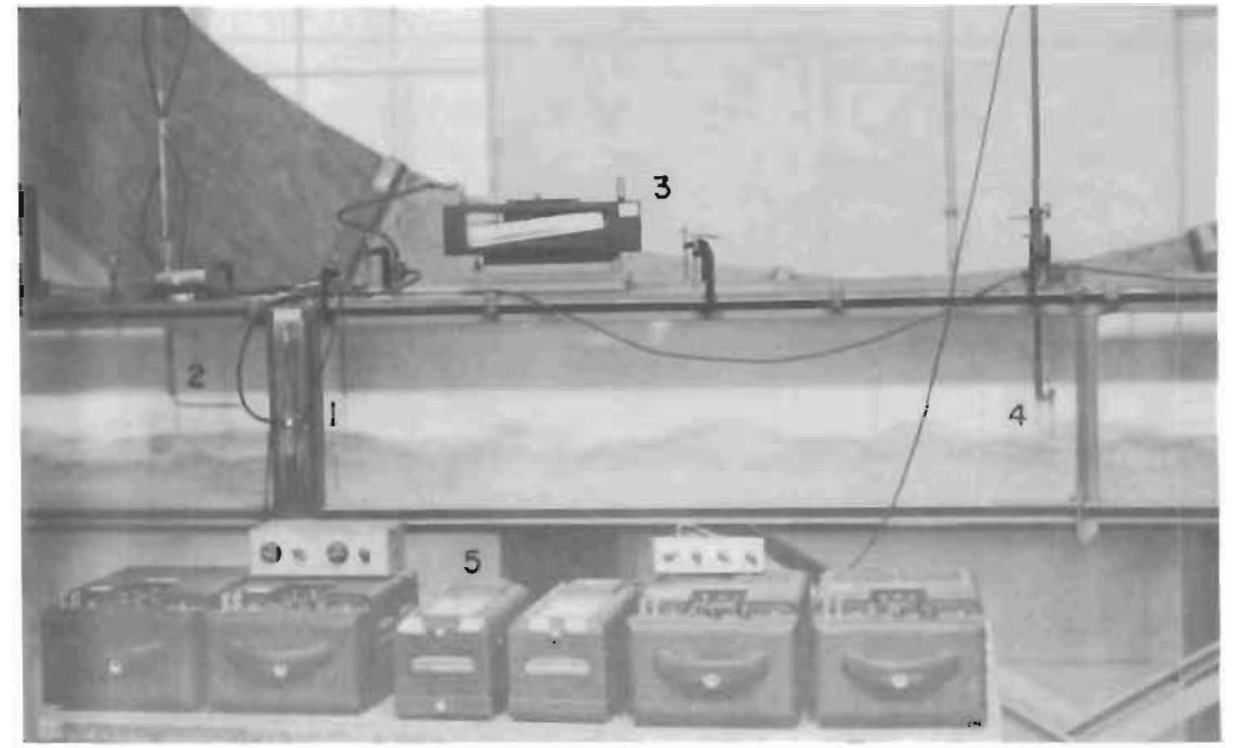

FIGURE 6 - A SECTION OF THE CHANNEL SHOWING MICROPIEZOMETER (1), PITOT TUBE (2), DRAFT GAGE (3), WAVE GAGE (4), AND BRUSH RECORDERS (5)

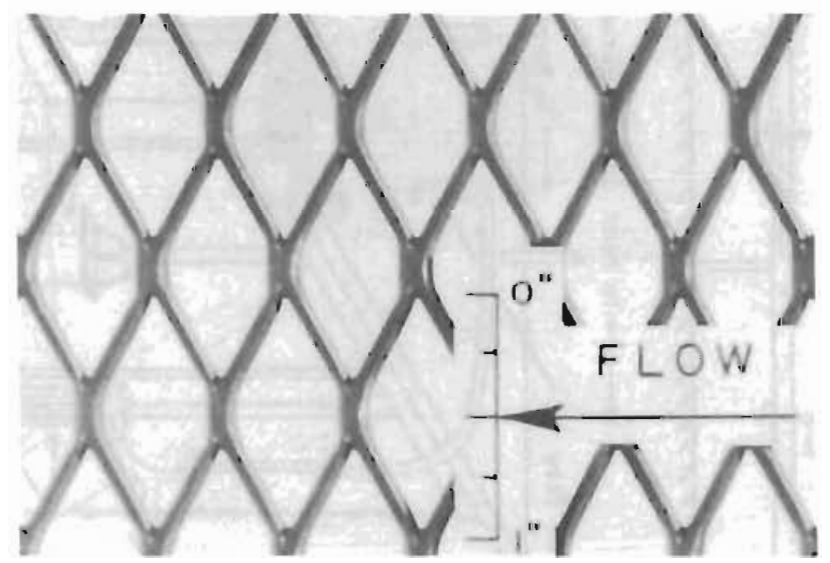

FIGURE 7 - EXPANDED METAL LATH USED

FOR CHANNEL BOTTOM ROUGHNESS

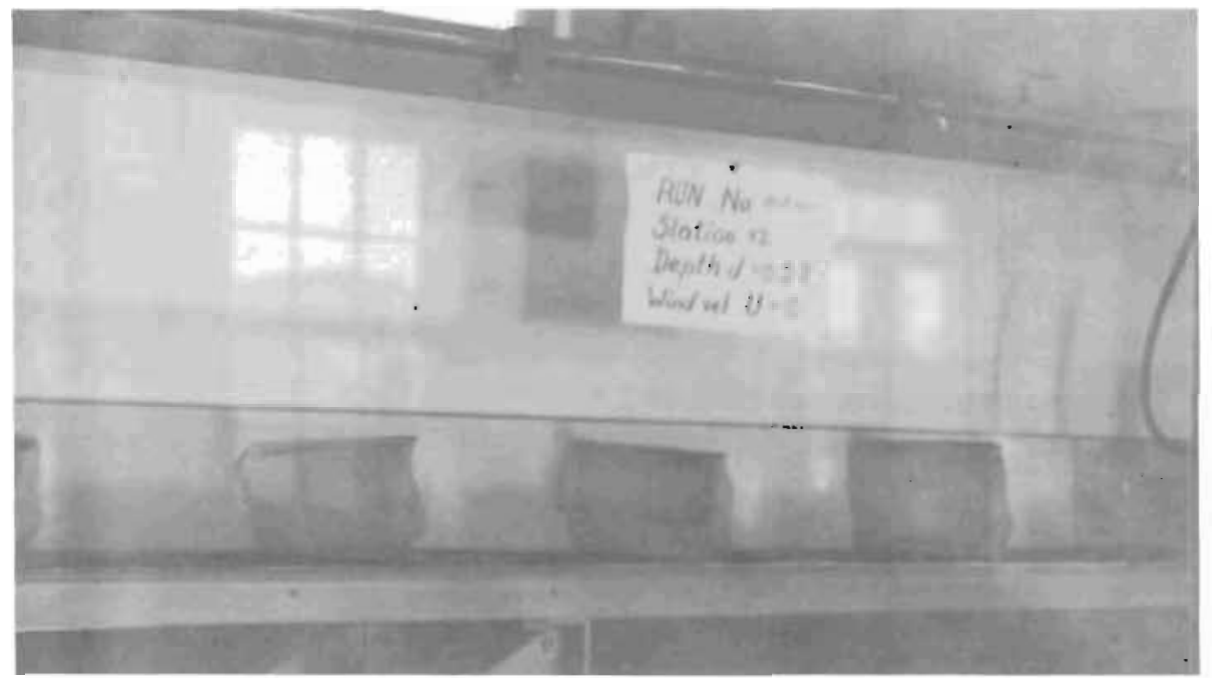

FIGURE 8 - CHEESECLOTH STRIPS USED IN CHANNEL TO SIMULATE VEgETATION 
the result of combined action of wind drag and pressure differences. To eliminate the effect of the variable pressure, the pressures were measured at each of five piezometers, as already described, and the measured surface profiles were corrected using the average pressure from these five measurements as their basis.

Experiments were performed using three different bottom roughnesses.

1. A smooth bottom was represented by the original bottom, painted with white oxide primer paint. The roughness for this type of bottom was determined in a laboratory flume and was found to be $\mathrm{k}_{\mathrm{g}}=0.0135$ foot in equivalent sand roughness, and the Mannings $\mathrm{n}=0.0116$. The experiments were completed with eight different depths $(0.05 ; 0.075 ; 0.100$, $0.150 ; 0.200 ; 0.250 ; 0.300$; and $0.370 \mathrm{ft}$. ) each of which was combined with 5 different wind velocities (approximately 1.; 15; 20; 25; and $33 \mathrm{ft} / \mathrm{sec}$.$) .$

2. A rough bottom condition was obtained by covering the smooth

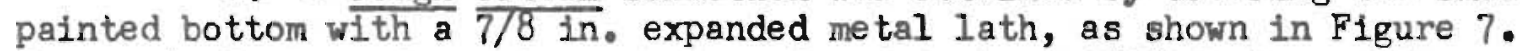
The equivalent sand roughness $k_{s}$ was found to be 0.0635 foot, and the Mannings $n=0.0207$. The experiments were made with 5 different depths $(0.050 ; 0.075 ; 0.100 ; 0.200$; and $0.370 \mathrm{ft}$.$) each combined with five$ different wind velocities.

3. A combination of the rough bottom and cheese cloth in the channel was introduced to simulate the roughness effect of vegetation in nature. The cheese cloth was fastened to the bottom across the entire width of the channel. The top of the cloth was made to float by the use of a thin piece of balsawood. The buoyancy of the cloth was kept to a minimum so that it could easily follow the current and the motion of water particles, as do natural grasses. The height of the cloth was approximately 0.30 foot, and constant, for all runs; hence, for the deepest depth of 0.37 foot used in the experiments, the top of the cloth was slightly below the SWL and for shallower depths it floated at SWL. One plece of cloth was used for each linear foot of channel. The arrangement is shown in Figure 8.

The experiments for this condition were performed using four different cepths $(0.05 ; 0.10 ; 0.20$; and $0.37 \mathrm{ft}$.$) each combined with the$ same five wind velocities used in the previnus experiments.

\section{RESULTS AND DISCUSSION}

The basic data are summarlzed in Table $I$ and the water-surface proflles plotted in Figures 9-11. (Table I appears at end of report.)

The water surface profiles were found to be parabolic, as was to be expected. The parabolic shape of the profiles was most pronounced for the combination of shallow water depths and high wind velocities. For the case of relatively deep water and relatively low wind velocities, the parabolic shaped water surface was found to be relatively flat, and could 


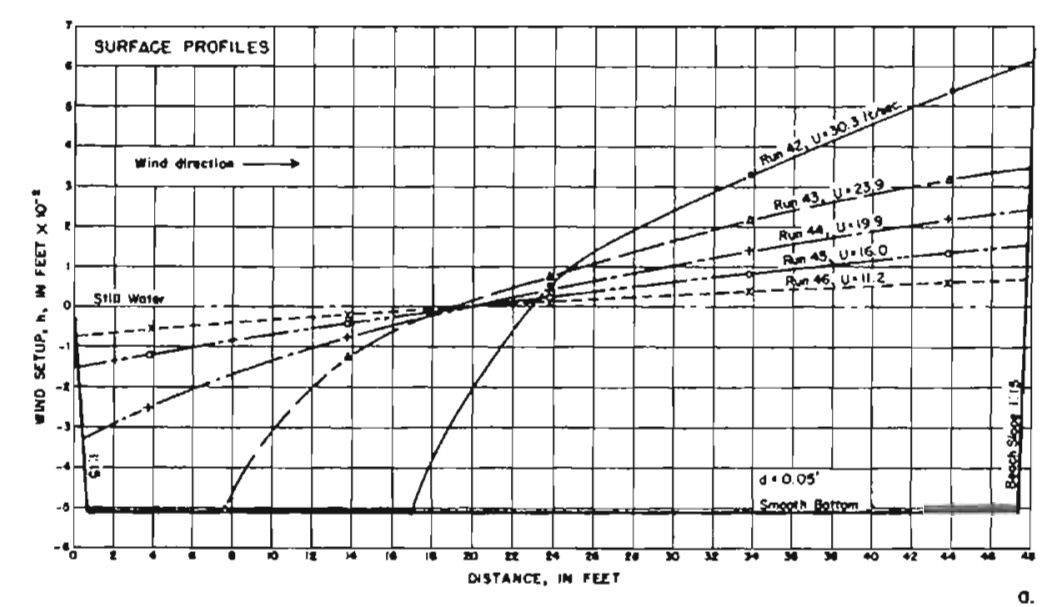

$\bar{\infty}$

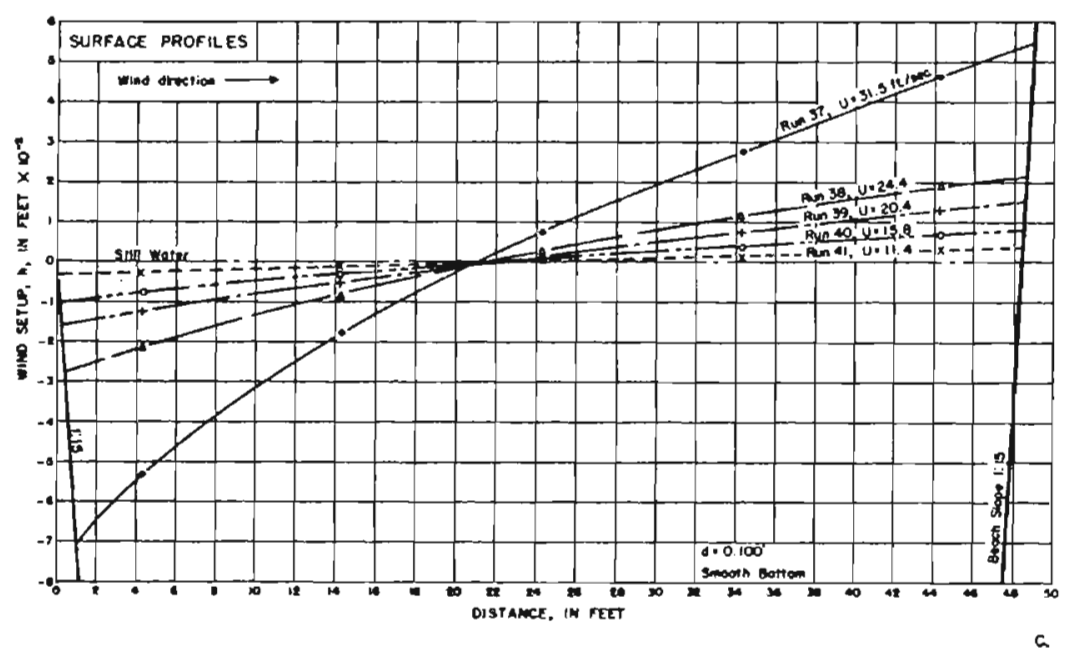

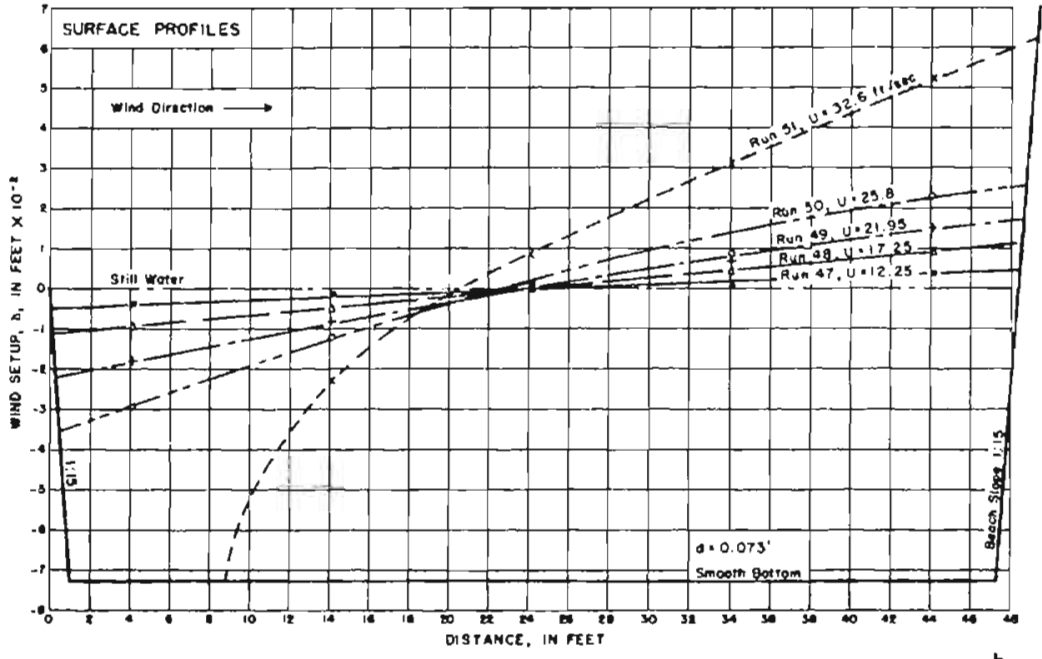

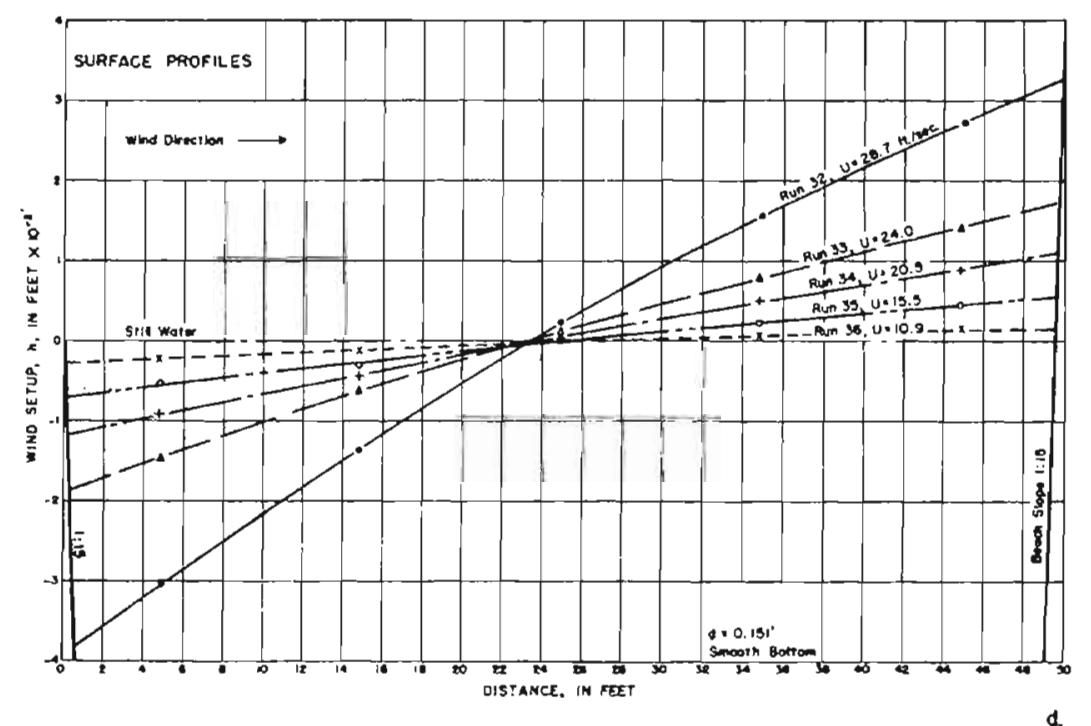

FIGURE $9, a-d \cdot$ SURFACE PROFILES 

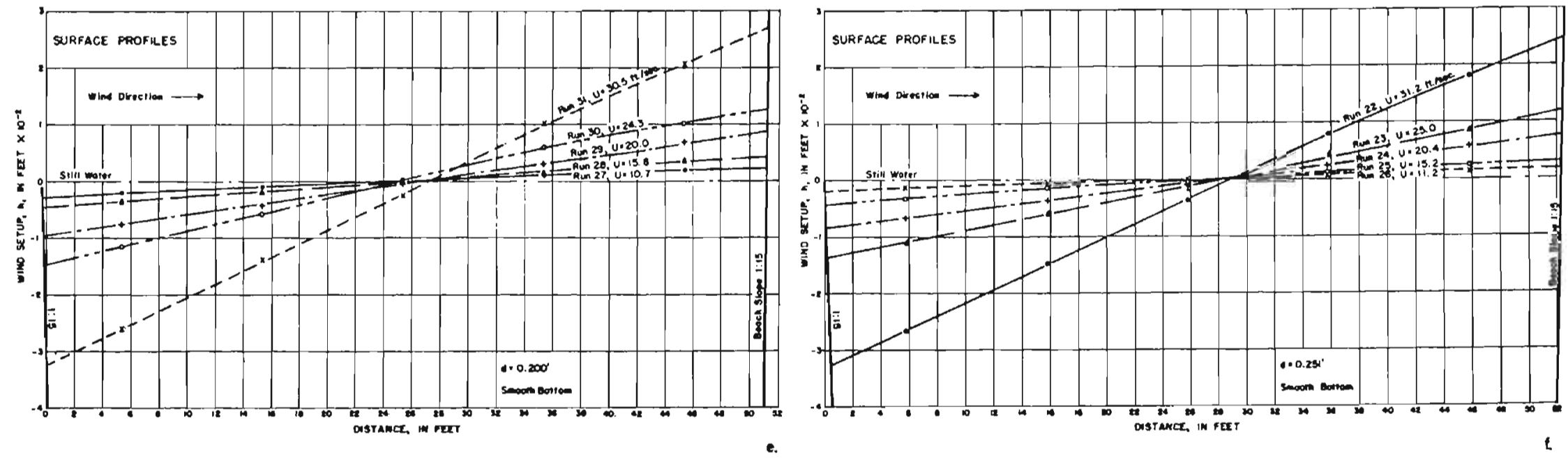

$\bar{\omega}$

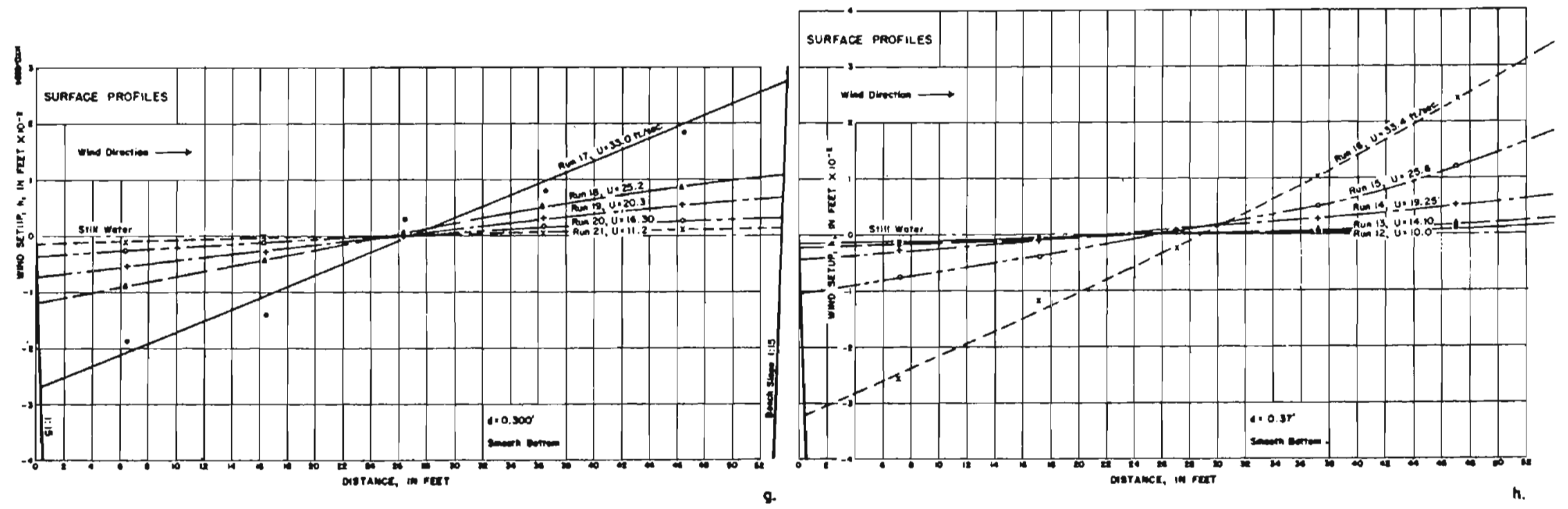

FIGURE $9, e-h \cdot$ SURFACE PROFILES 

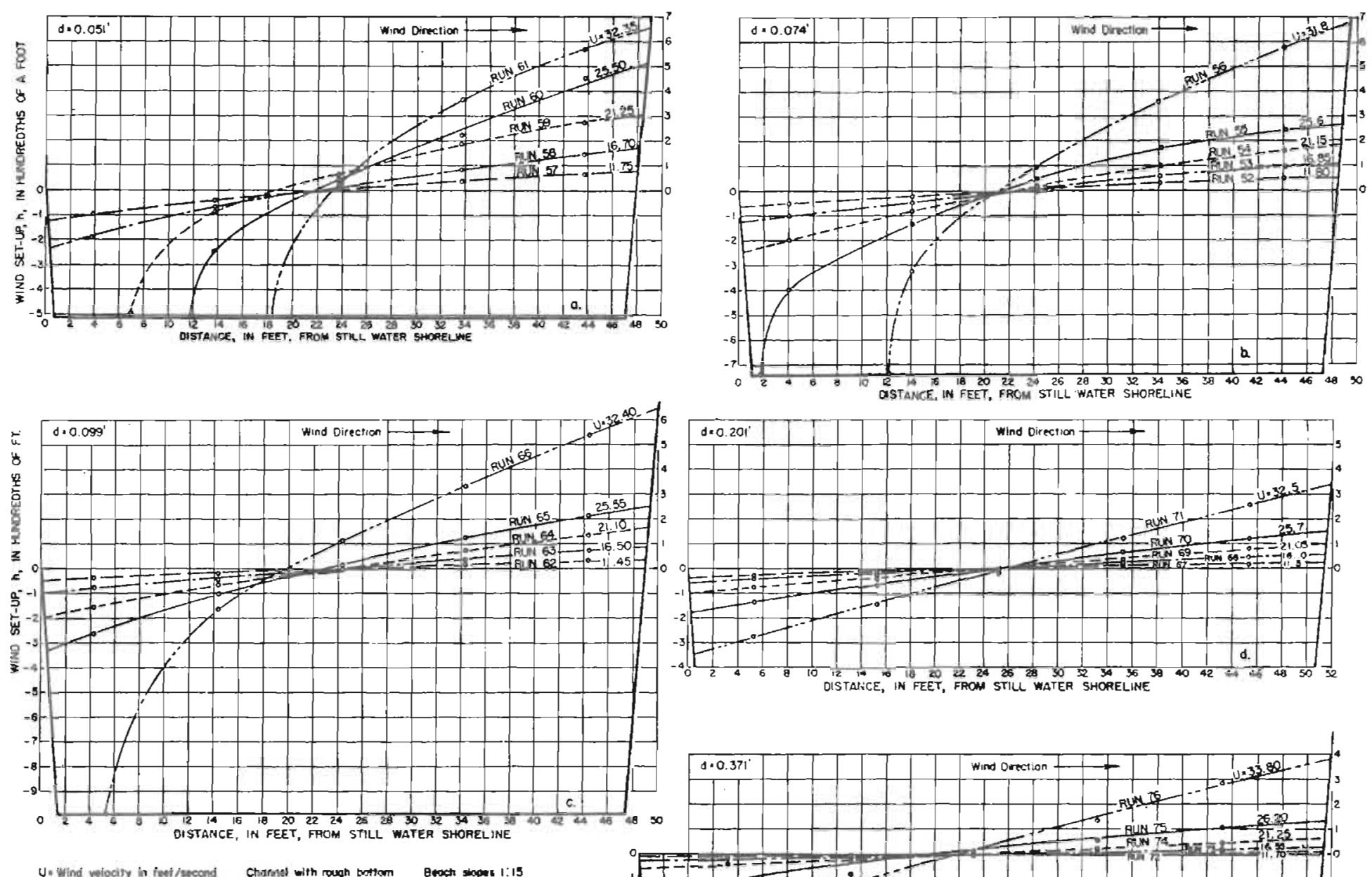

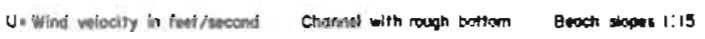

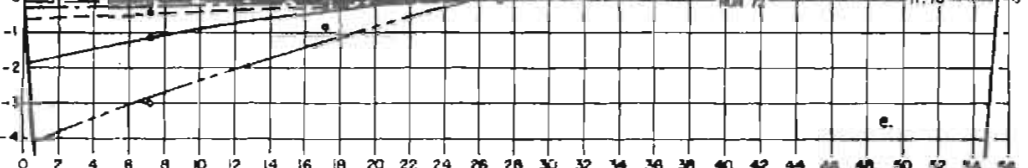

FIGURE 10 SURFACE PROFILES 

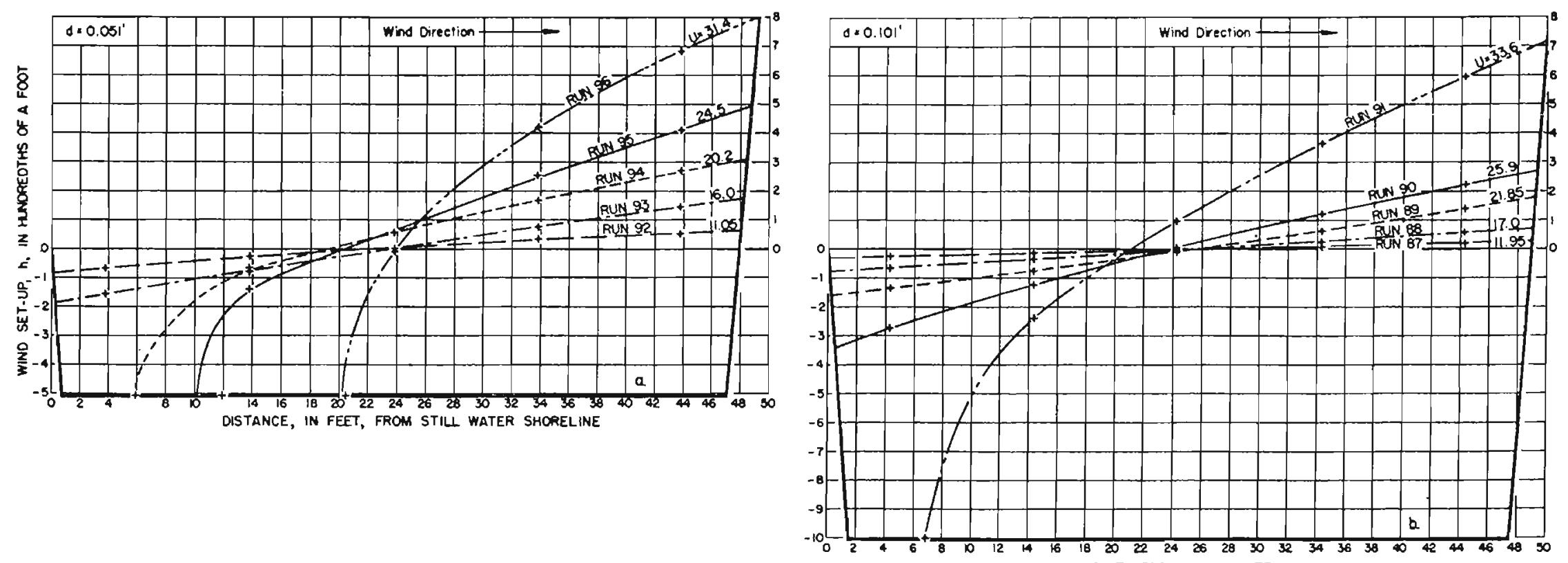

$\simeq$

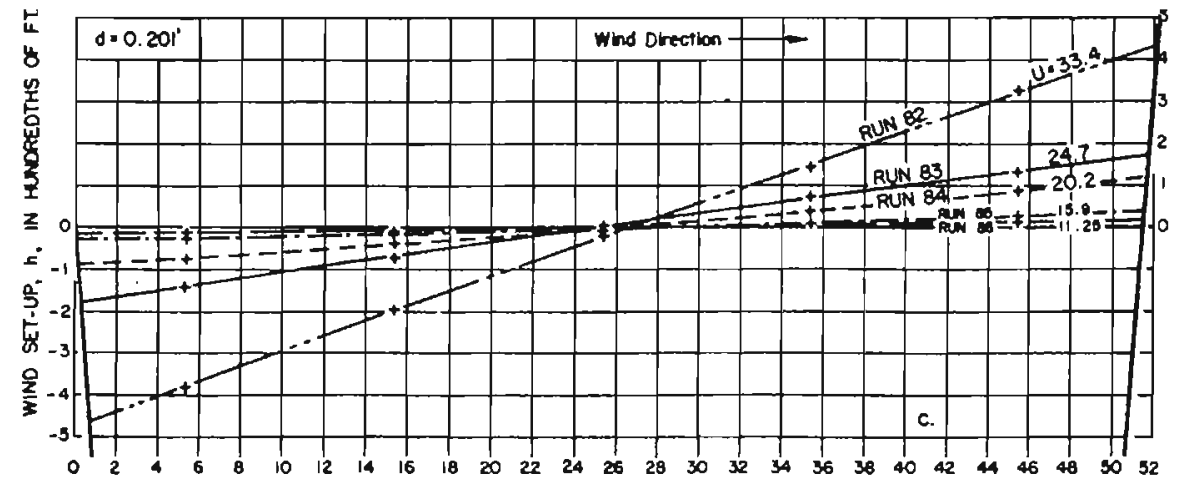
DISTANCE, IN FEET, FROM STILL WATER SHORELINE

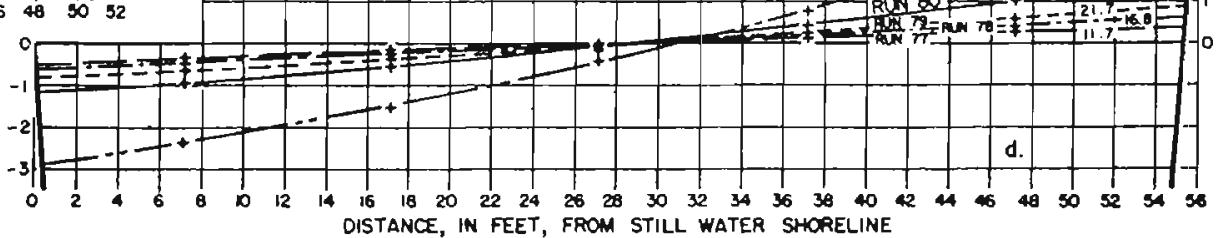

FIGURE II. SURFACE PROFILES 

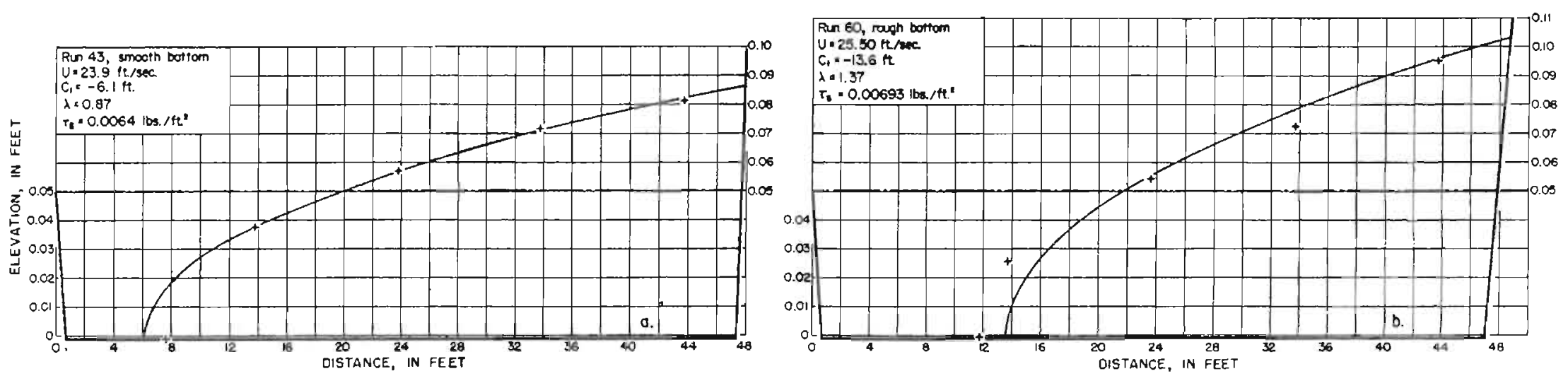

0.0 .051 it for figures o, b and $c$
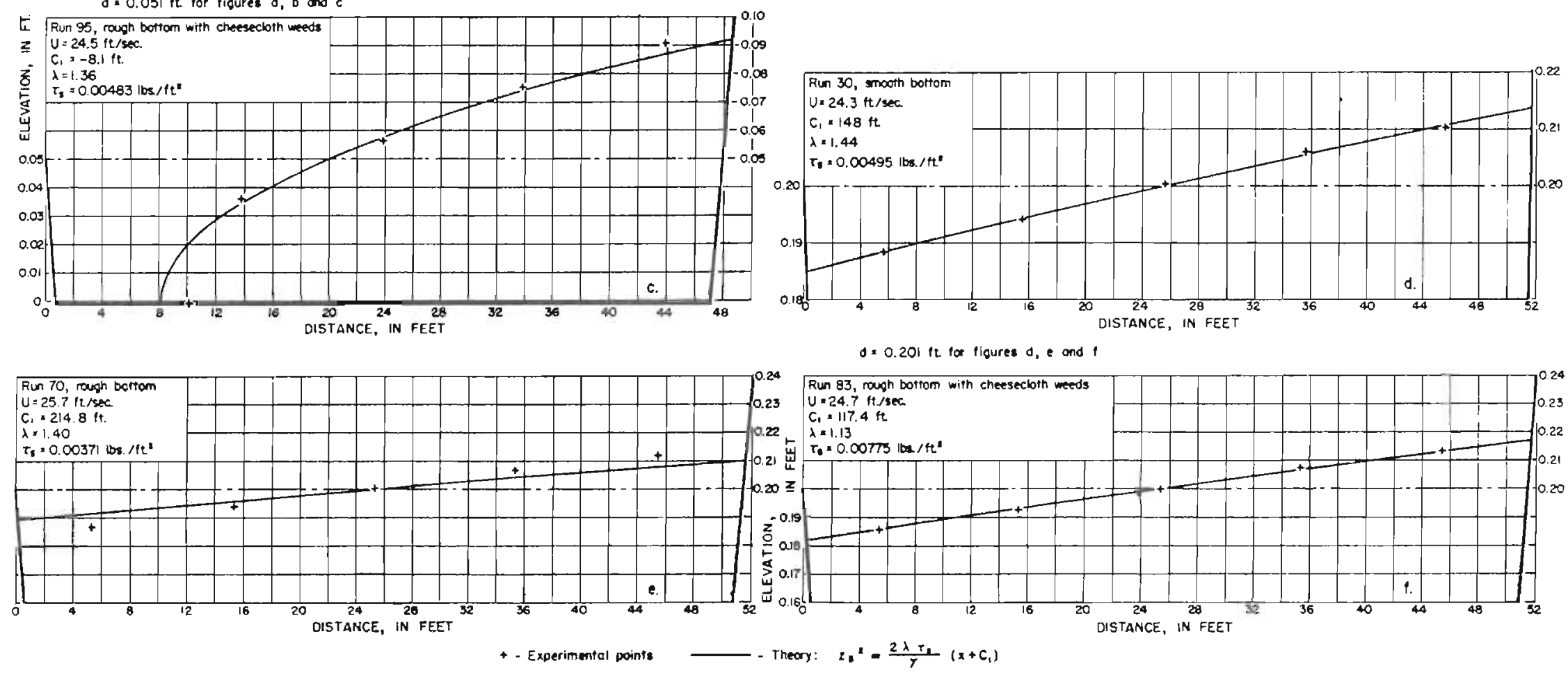

FIGURE I2. COMPARISON OF MEASURED WATER SURFACE PROFILES WITH THEORY 
with sufficient accuracy be replaced by a plane (compare with assumptions for Equations 27 and 28). The theoretical water surface profiles as given by Equation (24) were compared with laboratory measurements in Figure 12 for two depths and three conditions of bottom roughness. The wind shear stress $\tau_{S}$ in Equation (24) was evaluated from wind velocity profiles as previously described (11). The coefficient $\lambda$ was also determined experimentally (11). The values for $\tau_{S}$ and $\lambda$ in Equation (24) were obtained from Table I, Reference 11, under the given run numbers, as were the actual measurements for the given run. The constant $\mathrm{C}_{1}$ was evaluated by the method given by Hellstrom 3/, and described by Equation (24). The agreement between the actual measurements and the theory was found to be good except for Run 70 in Figure 12e, where the measured profile was about 30 percent steeper than the theory indicated. For cases with exposed bottom, the extent of exposure was not always predicted accurately, and it seemed that the extent of exposure was greater than the theory predicted. This may be a phenomenon which depends upon the experimental condition and such effects as surface tension, etc. In laboratory experiments it is very hard to determine the exact location of the water line on a level bottom. Also the surface tension may have a considerable effect in the very shallow region. The observed water surface in the region of the water line has very often the shape

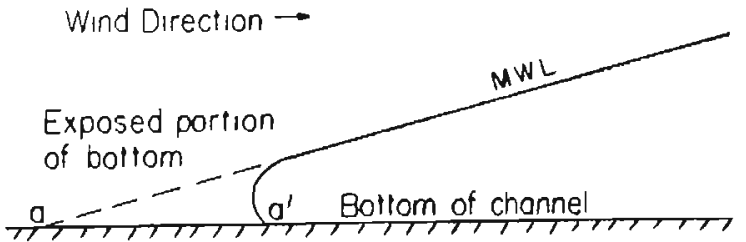

FIGURE 13 . shown by the heavy line in Figure13, and the water line is determined at $a^{\prime}$ instead of $a$.

The velocity distribution of the water flow is given by Equation (23) for turbulent flow. This equation was used to plot the theoretical velocity distribution curves in Figure 14 for depths 0.37 foot and 0.11 foot. No attempt was made to measure the actual flow velocities. Various qualitative observations (observing the motion of tiny particles)

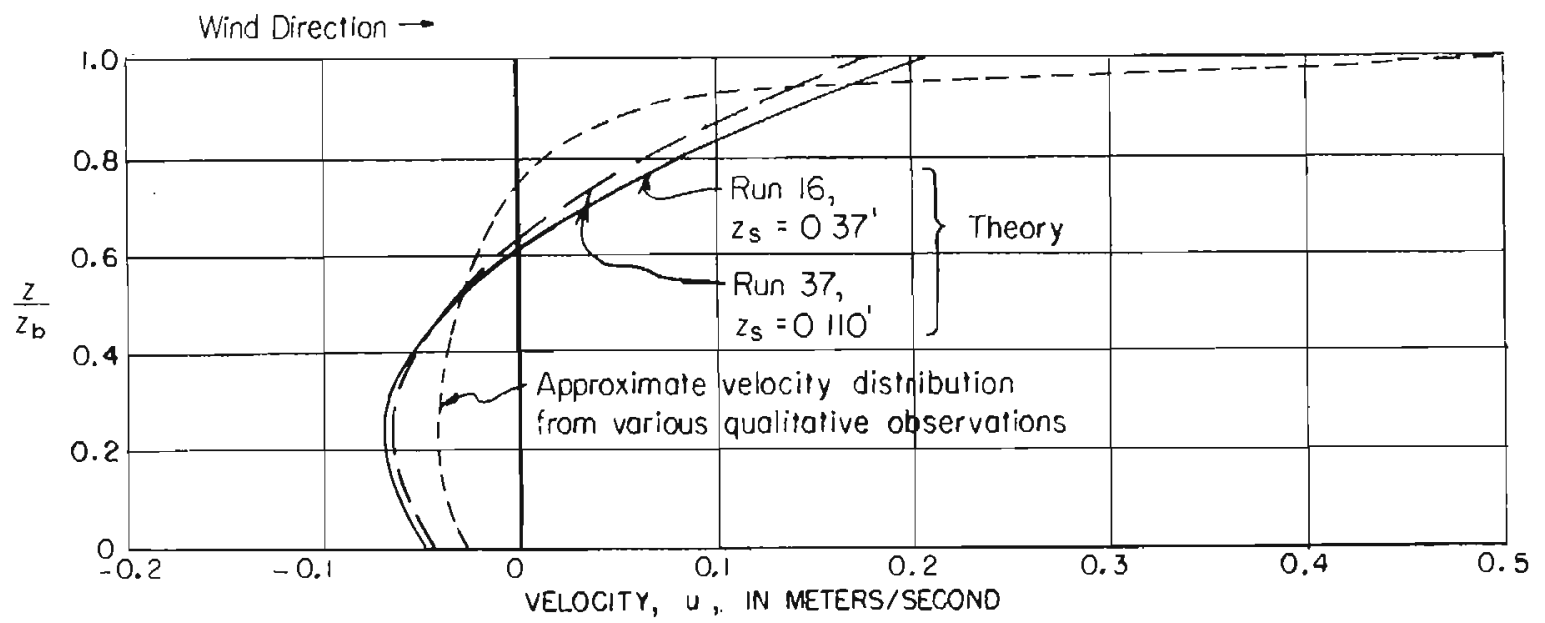

FIGURE 14.

Indicated, however, that the flow in wind direction was concentrated in 
a narrow region just below the water surface. The velocities on the water surface seemed to be higher than predicted by the theory, declining rapidly with depth. The approximate observed velocity distribution curve has been indicated in Figure 14. The curve should be considered as qualitative only, and as such it indicates the shape of the curve, but not the absolute values of velocity.

Current directions and intensities can be visualized by a study of Figures 15 to 17 , where strips of cheese-cloth were used to simulate vegetation. Figures 15 and 16 represent the case of relatively deep water $(0.37 \mathrm{ft.})$ as compared with the height of the cloth, and the top of the cloth (approximately $0.30 \mathrm{ft}$. high) floats slightly below the stillwater surface (see Figure 16a). When the wind velocity was increased, the magnitude of the drift and return flow also increased. The effect of the return. flow along the bottom was to incline the cloth in the direction opposite to that of the wind (marked with an arrow in the pictures). The effect of the return current was to pull the buoyant top of the eloth below the water surface. At higher wind velocities, the entire cloth was subjected to the action of the return flow (see Figures 15 and 16 c;d). In Figure 17 the water is shallow (0.10 ft.) as compared with the height of the cloth $(0.30 \mathrm{ft}$.$) . For lower wind velocity the cloth usually$ became inclined in the same direction as the wind, but at times it became inclined in the opposite direction (see Figure 17a), depending upon the buoyancy at the top of the cloth. In some cases the balsawood on the top of the cloth extended out of the water and was subjected to additional wind drag. When the wind velocity was increased above a certain magnitude, return flow was great enough to pull the top of the cloth below the water surface and out of the region of drift. Under these circumstances, the cloth reversed direction and inclined in the direction opposite to that of the wind (see Figure $17 \mathrm{~b}$ ).

In most practical cases, one is not as interested in the exact shape of the water surface profile as in the maximum elevations to be expected along the leeward shores. Because of this, only the set-up near the leeward shore is considered in the following discussion. The set-ups were measured at the location of Piezometer 5 (see Figure 5a) which was located near the toe of the leeward beach in a constant depth of water. The fetch, F, is the distance from the still water beach line at the windward shore to the point of measurement at Piezometer 5. The relationship between set-up and wind velocity is presented in Figures 18 and 19. It $c$ an be seen that smooth curves fit the experimental points in a satisfactory manner. In Figure 20 the set-up as a function of the depth of water is given for 5 different wind velocities (10; 15; 20; 25;

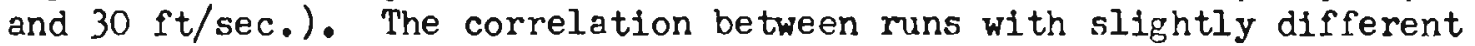
wind velocities and fetch lengths was obtained by graphical interpolation of the experimental values. Figure 20 demonstrates clearly that the set-up increases rapidly when the depth of water decreases below a certain value. This "critical" depth seems to be related to wind velocity with the stronger the wind, the deeper the critical depth.

The various theoretical formulas, as discussed in a previous section, were compared with experimental results in Figures 21 and 22 . In general, 

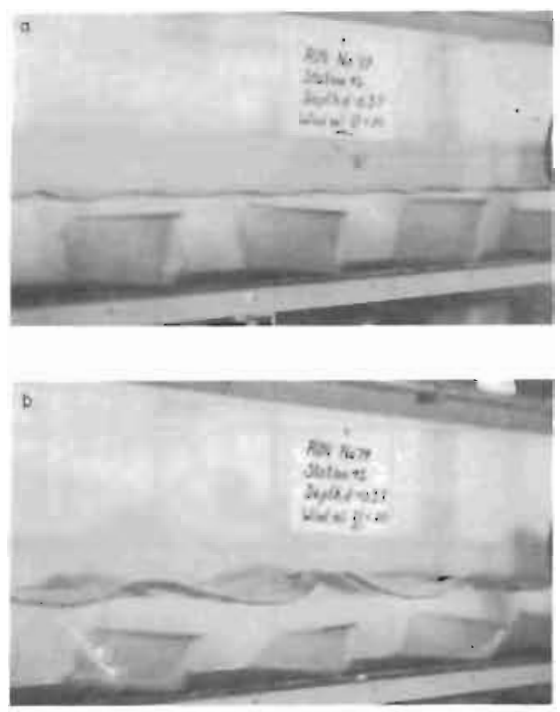

No
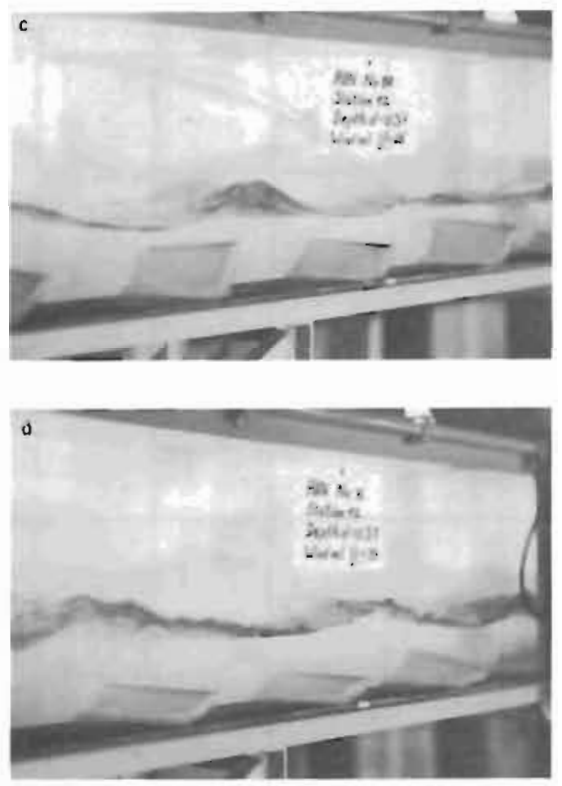
FIGURE IS. RELATIVELY DEEP WATER
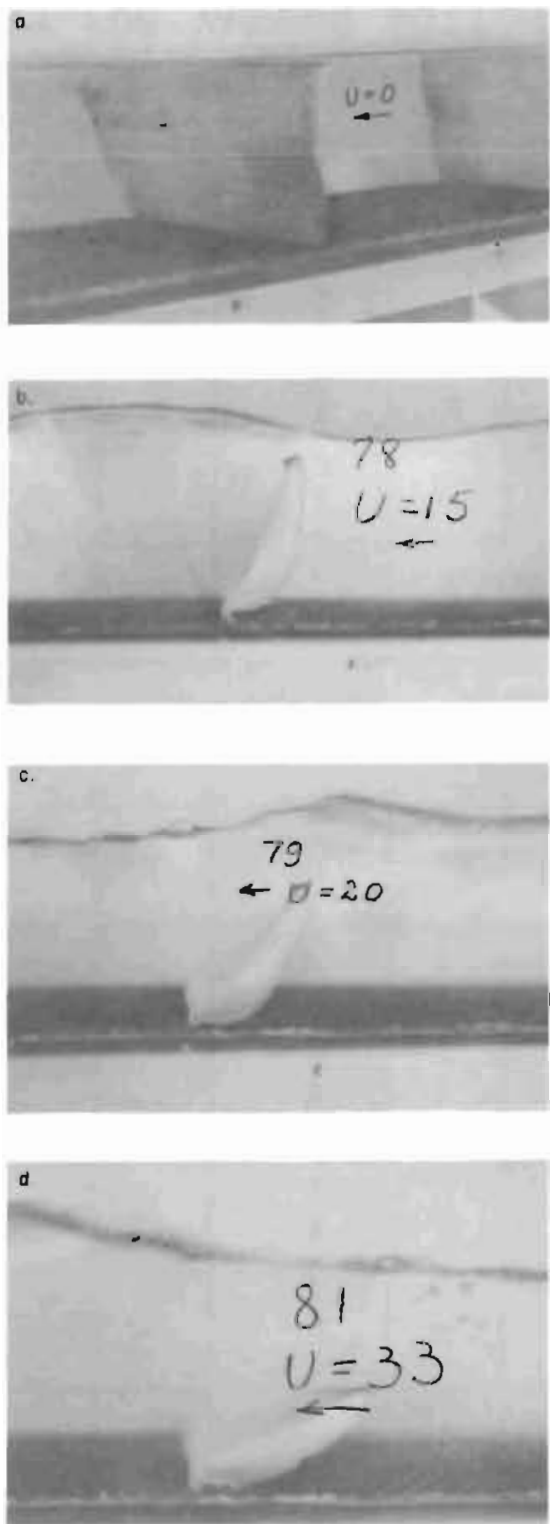

FIGURE $16 \cdot$ CLOSE - UP OF CLOTH
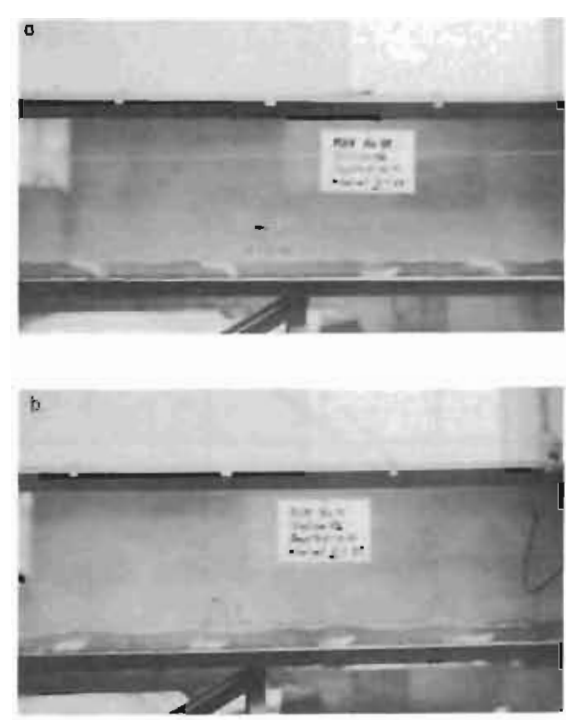

FIGURE IT RELATNELY SHALLOW WATER
AS COMPARED WITH THE LENGTH OF CLOTH

FIGURES 15, 16, 17. CONDITION WITH CHEESECLOTH N CHANNEL TO SIMULATE VEgetaTION 

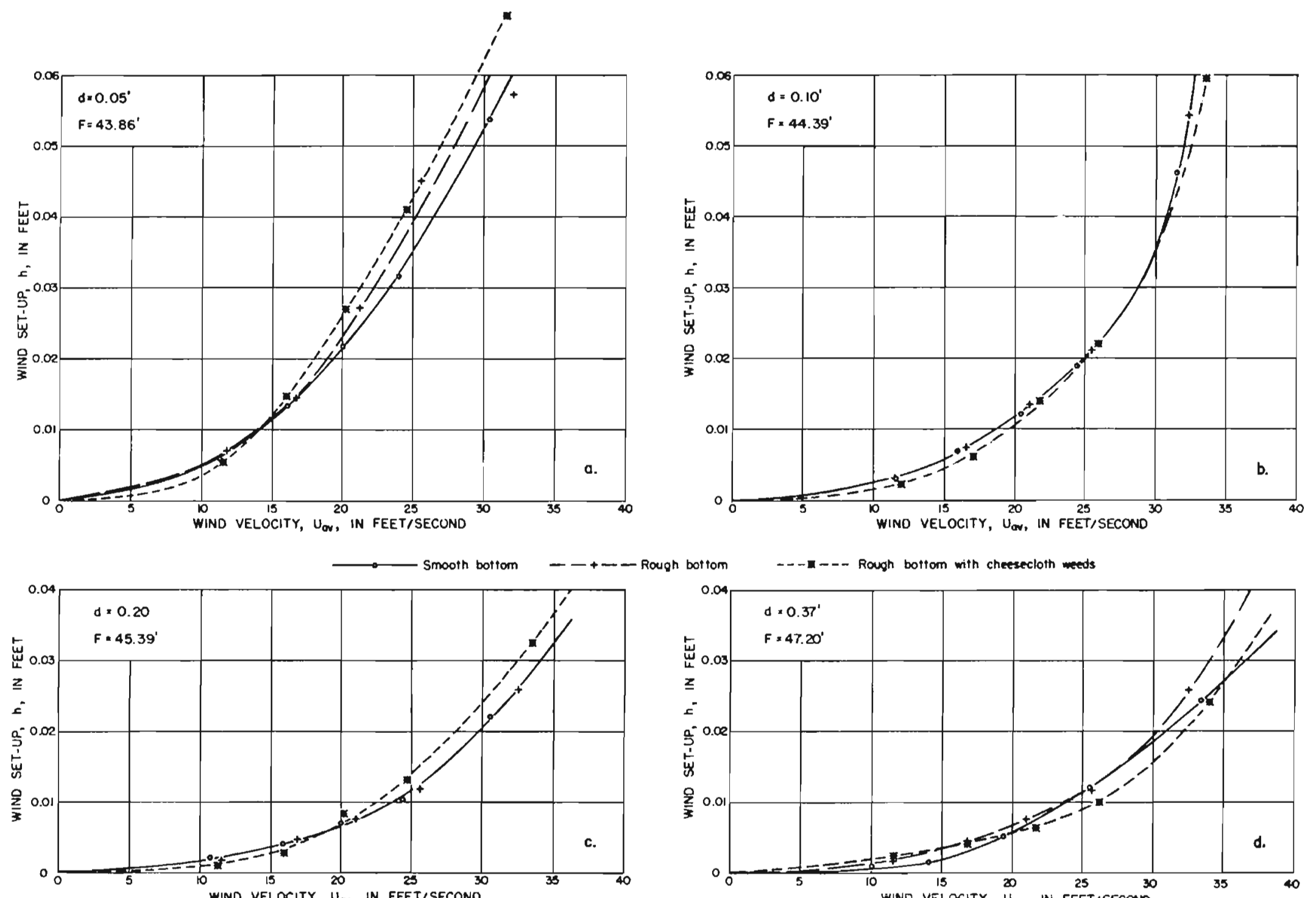

FIGURE I8 - WIND SET - UP AS A FUNCTION OF WIND VELOCITY FOR VARIOUS BOTTOM ROUGHNESSES 


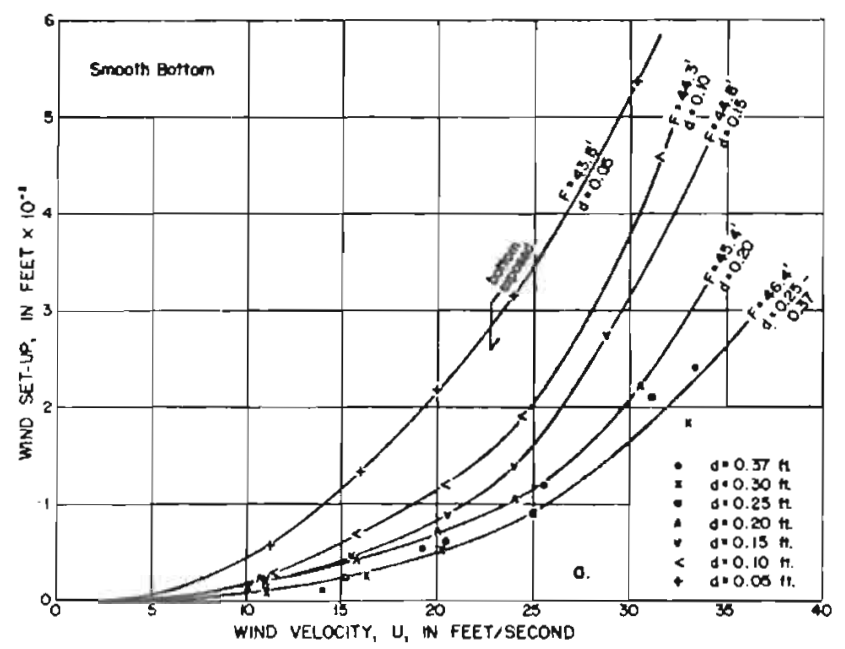

$\stackrel{v}{2}$
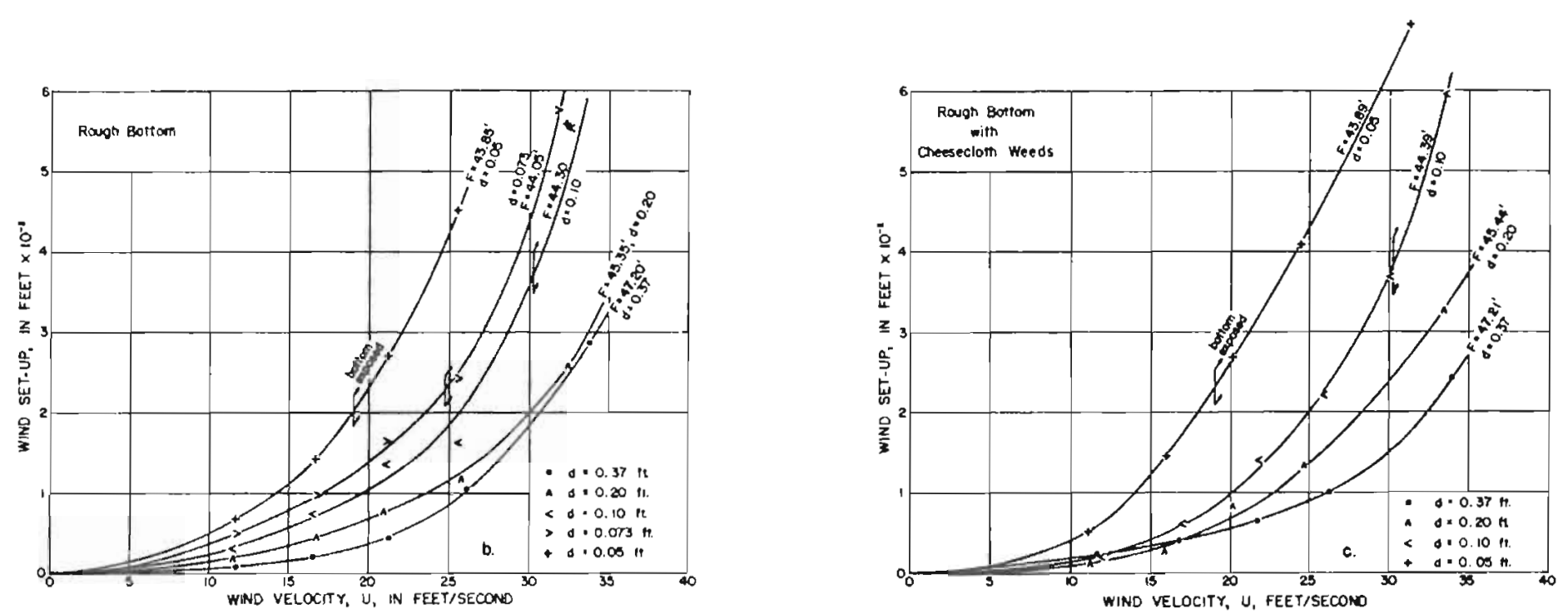

FIGURE 19. WIND SET - UP AS A FUNCTION OF WIND VELOCITIES FOR SEVERAL DEPTHS AND ROUGHNESES 


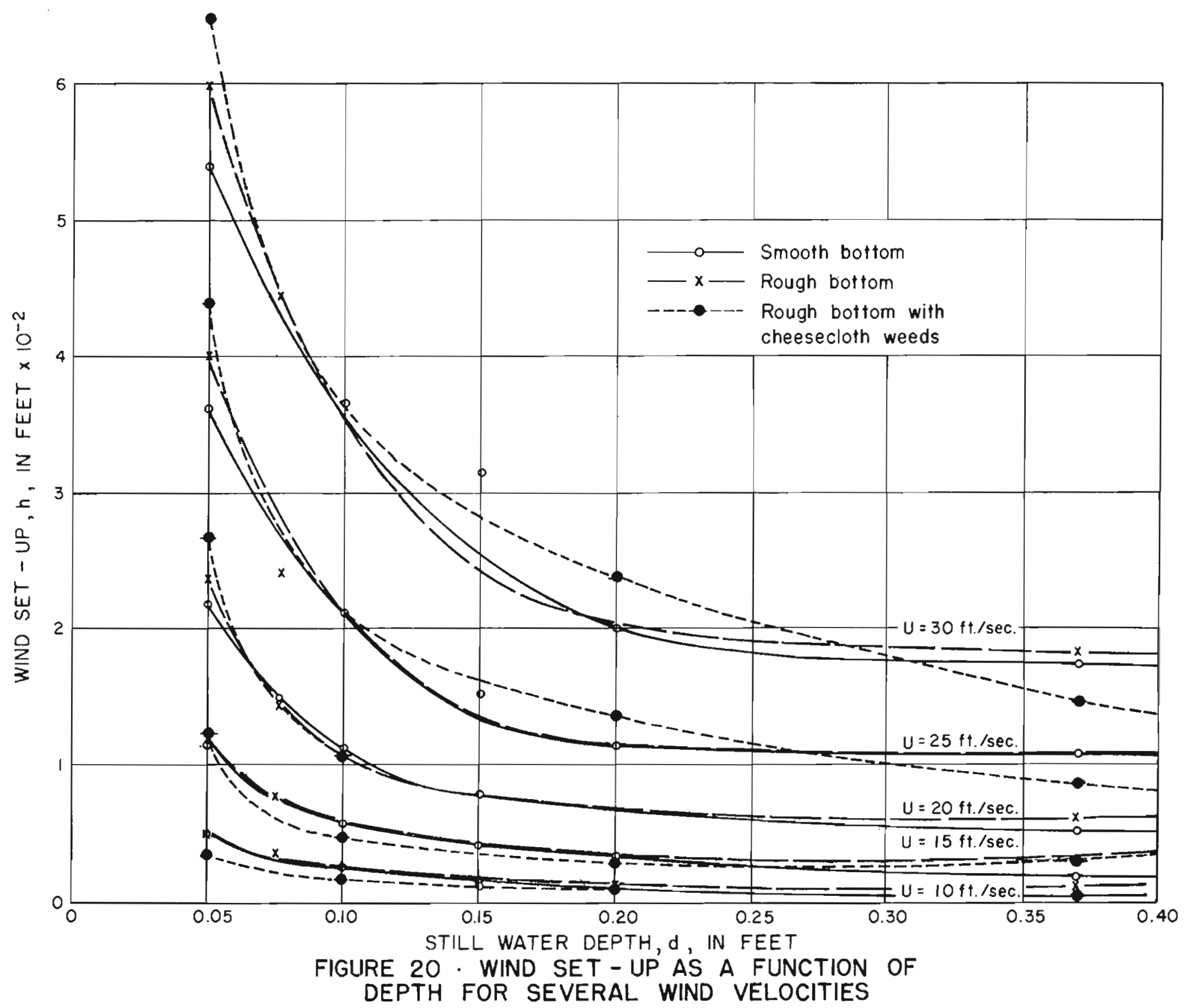



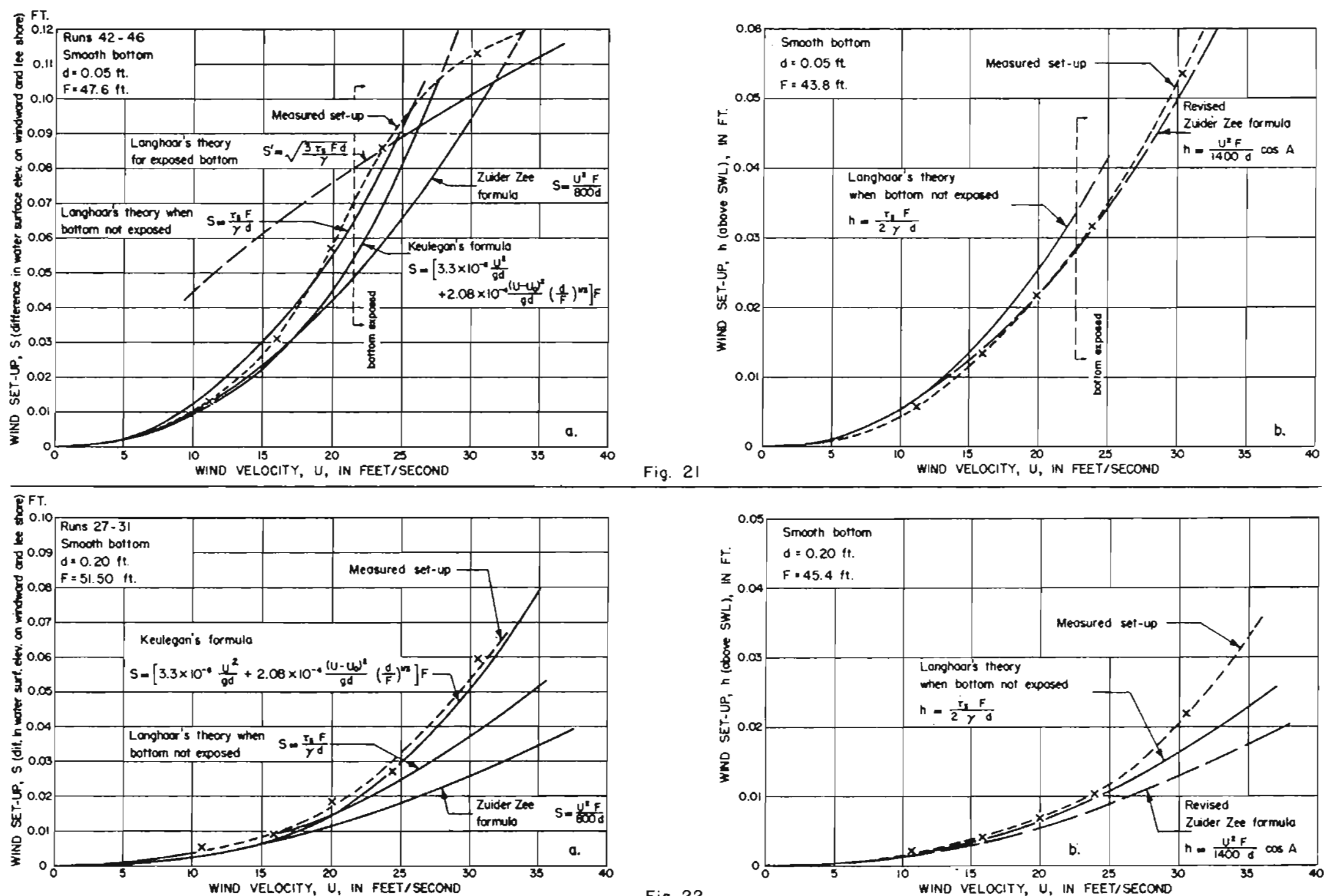

Fig. 21

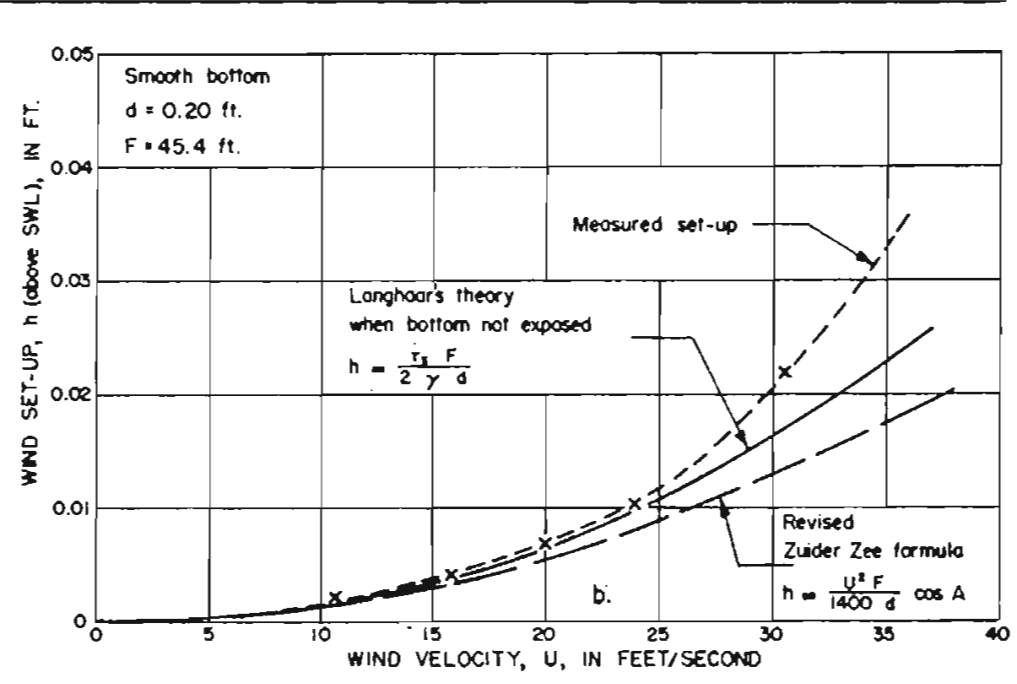

COMPARISON OF VARIOUS THEORIES WITH EXPERIMENTAL LABORATORY RESULTS 
the formulas could be divided into two groups: (a) the formulas giving the difference $S$ between the water-surface elevation at the windward and the leeward shore, and (b) the formulas giving the set-up, $h$, at the leeward shore above the SwL. In addition to the se two groups, the Langhaar exposed bottom formula, as given by Equation (30) should be considered separately. The set-up in this formula is essentially the difference between the windward and leeward water-surface elevation, but the windward water-gurface elevation must be taken in this case to be the elevation of the exposed horizontal bottom. Because the bottom is horizontal, this elevation remains a constant for all conditions of exposed bottom. Plotting the set-up agalnst the wind veloc1ty(Figure 2la), Langhaar's formula for exposed bottom results in a curve which has a slope that decreases with increasing wind velocity. The other formulas for non-exposed bottoms result in a curve with a slope which increases as the wind velocity increases. To distinguish between the exposed bottom and the non-exposed bottom formulas, the set-up as measured above the horizontal bottom for exposed bottom formulas is indicated by $S^{\prime}$ and the set-up above the SWL is indicated by $h^{\prime}$, rather than $S$ and $h$.

The formulas in groups (a) and (b) cannot always be interchanged by setting $S=2 \mathrm{~h}$. This can be done only when the wind effect is small; that is, when the surface proflle approaches a straight line and the nodal point is located halif way between the windward and leeward shore. When the wind effect increases, the profile will. assume a parabolic shape and the nodal point will move toward the windward shore, as can be seen from Equation (26) and as has been demonstrated by the laboratory experiments (Figures 9 to 11 ).

Group (a) is represented in Figures $21 \mathrm{a}$ and $22 \mathrm{a}$, The experimental curves in these figures were plotted using data from Figures 9 a-e. The experimental data were compared with the Langhaar and the Keulegan. theories, and the Zuider Zee formula. Keulegan's formula seems to fi.t the data the best. when the water is not too shallow and the surface proflle approaches more or less a straight-line. Langhaar's formula gives a better fit for cases with very shallow water, as is the case shown in Figure 2la. Keulegan's formula is also fairly reliable in thia case, provided that the bottom is not exposed. For exposed bottom conditions, use of Keulegan's formula may lead to overestimation of the set-up, depending upon the degree of exposure. Langhaar's theory shows good agreement when the curve of the non-exposed bottom thecry is rollowed until it intersects the curve of the exposed bottom theory and then the latter is followed. The exposed bottom theory seems to give somewhat smaller values than measured, so that the change of the constant 3.0 in Equation (30) to 3.373, as introduced by the Corps of Engineers in Eauation (31), may be recommended. The wind shear stress is in Langhaar's formula was taken from Figure 11 of Reference 11 , and represents an average of the actual measurements for the same experiments and conditions. For different cases, the accuracy of prediction will obviously depend very much upon the proper estimation of wind shear stresses at the water surface. 
$\mathrm{U}_{0}$, in Keulegan's formula, was given in Reference 7 for five different depths of water. These data were plotted in Figure 4 in this report and a smooth curve was drawn through them. This curve was used to determine $U_{O}$ for the given particular case 5.

The Zuider Zee formula as given by Equation (38) also has been compared with measurements (Figures $21 \mathrm{a}$ and 22a). It can be seen in both figures that use of the formula leads to an underestimation of the set-up for laboratory experiments.

The set-up, $h$, above the SWL has been compared with the formulas of group (b) in Figures $2 \mathrm{lb}$ and $22 \mathrm{~b}$. Langhaar's formula actually belongs to group $(a)$, but as has been pointed out, $S=2 h$ when the surface profile approaches a straight line. The experimental data were obtained at the location of Piezometer 5 and plotted as given in Table I.

The revised Zuider Zee formula (Equation 39) gives the best agreement for shallow water (Figure 2lb), while for deeper water it leads to underestimations of the set-up for laboratory experiments. Use of Langhaar's formula leads to overestimations of the set-up for shallow water. The overestimation may be due to the assumption that $h=5 / 2$. In actual cases, however, $h<S / 2$ when the wind effect is large as compared with the depth of water. In deep water, use of Langhaar's formula seems to lead to underestimation of the set-up, especially for higher wind velocities.

Langhaar's theory does not consider the increase in form drag due to the presence of waves. In shallow water the wave heights are usually small and so the increase in form urag may be negligible, while in deeper water and for higher waves, it has to be included in computations. This is demonstrated in Figure $22 \mathrm{a}$, where use of Langhaar's formula leads to underestimations of set-up for higher wind velocities, while use of Keulegan's formula, where the increase in form drag due to the waves is included, leads to results which fit the experimental curve very closely.

The effect of bottom roughness has been demonstrated in Figures 18 to 20. When the bottom roughness was increased from $n=0.012$ for the smooth bottom to $\mathrm{n}=0.021$ for the bottom covered with expended metal lath, the set-up at the leeward end did not change, except, for very shallow depths, as has been shown in Figure 18 a and 20. For the shallowest still-water depth $(0.05$ foot) used in this set of experiments, the set-up was further increased by adding cheese cloth in the channel to simulate vegetation; then the shape of the curve indicating the set-up in Figure 20 was changed slightly. Figure 20 indicates that for deeper water depths the set-up may be smaller than for the smooth bottom, but in shallow water it seems to be definitely higher. For the depth 0.05 foot the set-up was approximately 20 percent higher than the set-up for the smooth bottom. The slope of the set-up curve was steeper when the cheese cloth was present than was the slope of the set-up curve for the smooth bottom.

Qualitative observations indicated that the time necessary to reach equilibrium set-up at the leeward end of the channel was longer for the 
rougher bottom. For the experiments with cheese cloth, it was found that the time to reach equilibrium was much longer than was the case for the experiments with the smooth bottom. On the other hand it was found that the roughness acted to dampen oscillations. For the smooth bottom the set-up usually exceeded for a short time the equilibrium position when the wind was started, and came to rest only after many oscillations about the equilibrium. When the blower was turned of $a$ bore was established which was reflected back and forth in the channel many times. The bottom roughness acted to dampen this bore so that the water surface became calmed much more rapidly for rough bottom conditions than for the smooth bottom.

Natural lake beds are very often covered with reeds and saw-grass which may be very dense and extend a considerable distance above the water surface; even the wind distribution and intensity above the lake may be affected. The reeds and saw-grass cannot follow the flow as easily as seaweed does (Figures 15 to 17), and so the flow may be considerably different for this condition. At the present time there are no data available to indicate what effect these types of vegetation have on wind tides. Further study should cast more light on this important phase of the problem.

Derivation of an Empirical Relationship

A consideration of the various terms of the formulas shows that the following dimensionless arrangement can be used to represent the relationship between the set-up and the other variables:

$$
\left(-\frac{h}{d}\right)=f^{\prime}\left(\frac{U^{2}}{F g}\right)
$$

These dimensionless parameters were used to plot all the data on a loglog scale in Figure 23. The experimental points in this figure fit a family of straight lines fairly well, indicating that the relationship has the following form:

$$
\left(\frac{h}{d}\right)=f(F / d)\left(\frac{U^{2}}{F g}\right)^{a}
$$

The " $f(F / d)$ " and "a" were evaluated from Figure 23 for various conditions and replotted in Figure 24 as functions of the fetch-depth relationship. There is some scatter of experimental points in Figure 24 , but in general the points fit a straight line. By extending the data beyond the laboratory limits, the average line in Figure 24 a was used to determine " $f(F / d) "$ for Lake Okeechobee, Baltic and Ringskobing Fjord. Using the avallable data for the above named bodies of water, $3,4,6,22 /$ an average value for " $a$ " was computed for each case and plotted in Figure $24 \mathrm{~b}$. The points so determined closely fit the same straight line as determined by the laboratory experiments. Provided that the relationship is valid for other conditions in nature, one could determine from Figure 24 $" f(F / d) n$ and $" a^{n}$ for the given fetch-depth relationship F/d. Applying 


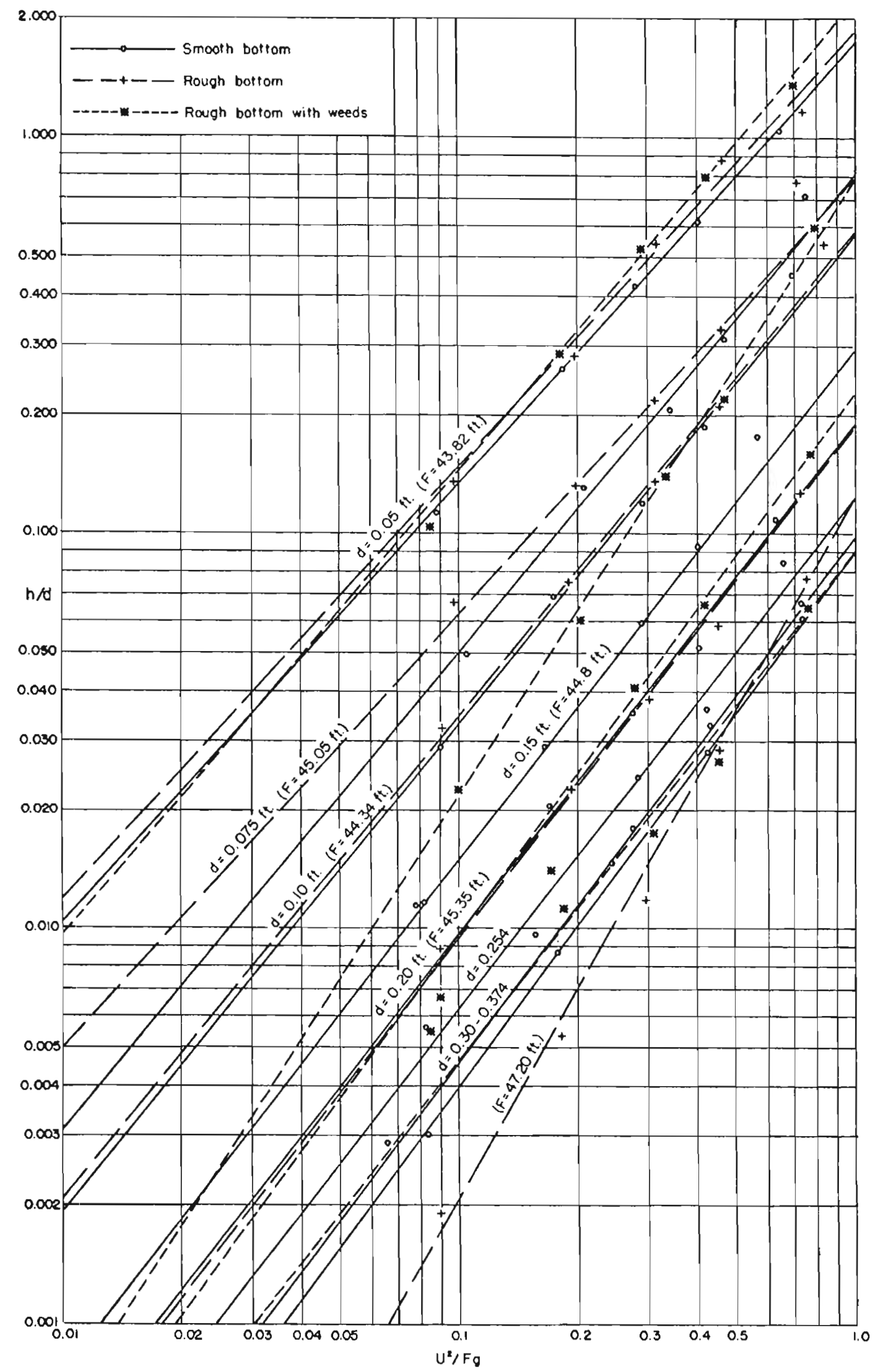

FIGURE $23 \cdot \mathrm{h} / \mathrm{d}$ versus $\mathrm{U}^{2} / \mathrm{Fg}$ 

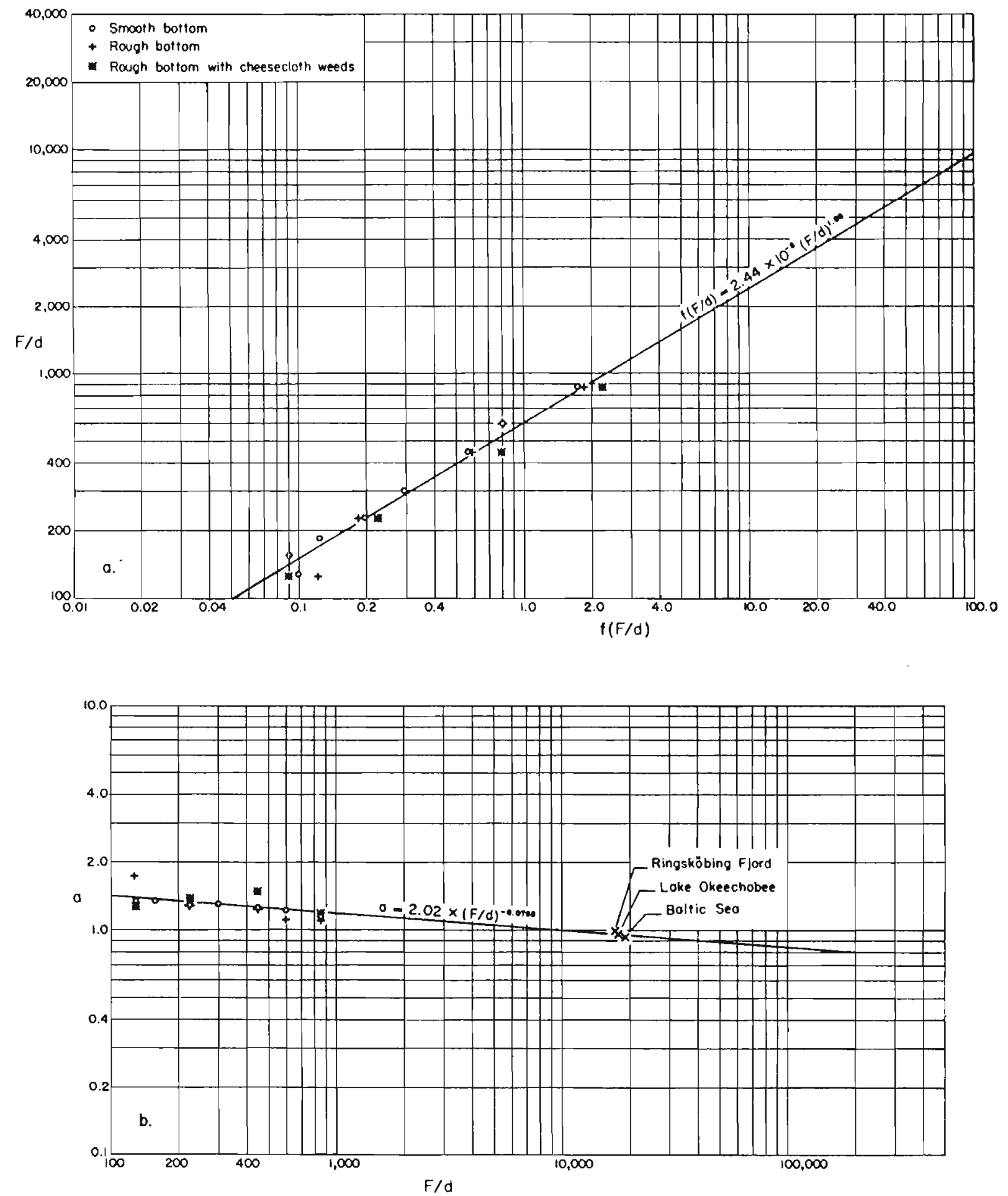

FIGURE $24 \cdot F / d$ versus $f(F / d)$ \& a versus $F / d$ 
this value in Equation ( $4 I$ ), the set-up can be predicted. To simplify the computations, Equation ( $4 I)$ together with Figure 24 were used to draw a nomographic chart. (Figure 25, Parta $T$ and TI). Figure 25, Part $T$ can be used for laboratory experiments and for the smaller bodies of water, while Part II of Figure 25 is useful for larger lakes.

To describe the applications of Figure 25, the following three examples are given:

1. Assume that we are using the nomographic chart to predict the set-up in a laboratory channel similar to that used in our experiments. The data are as follows: Wind velocity, $U=25 \mathrm{ft} / \mathrm{sec}$.; Fetch, $F=45$ $\mathrm{ft.}$; and depth of still water, $d=0.10 \mathrm{ft}$. From these data: $\mathrm{U}^{2} / \mathrm{Fg}=4.32 \times 10^{-1}$ and $\mathrm{F} / \mathrm{d}=450$.

Enter the left side of Figure 25, Part T, with $U^{2} / \mathrm{Fg}=4.32 \times 10^{-1}$ and turn the ray by 90 degrees (as shown by the dotted Iine) each time it meets the line for $F / d=450$ until we obtain $h / d=0.21$ in the right, portion of the chart. Knowing $d=0.10$ foot, we compilte $h=0.021$ fnnt. Comparison with Flgure 20 indicates that this value agrees very closely with the measured value.

2. Using the graph for a large lake, we use Part JJ of Figure 25. Let us assume $U=50 \mathrm{ft} / \mathrm{sec}$; $F=35 \mathrm{mi} .=185,00 \mathrm{ft}$; $\mathrm{d}=8.0 \mathrm{ft}$. From this data we have $\mathrm{U}^{2} / \mathrm{Fg}=4.20 \times 10-4$, and $\mathrm{F} / \mathrm{d}=23,100$. Entering, the graph with the given $\mathrm{U}^{2} / \mathrm{Fg}$, we obtain $\mathrm{h} / \mathrm{d}=0.278$, hence $\mathrm{h}=2.23 \mathrm{ft}$.

3. For the third example, let us assume that the lake is the same as in Example 2, but the wind velocity is $U=80 \mathrm{ft} / \mathrm{sec}$. Hence we have $\mathrm{U}^{2} / \mathrm{Fg}=1.08 \times \mathrm{l} 10^{-3}$ and $\mathrm{F} / \mathrm{d}=23,100$. The resultant $\mathrm{h} / \mathrm{d}=0.67$, and $h=5.35 \mathrm{ft}$.

The graphs in Figure 25 may be used for lakes with uniform or nearly unform depths and widths across the entire fetch, and the tide axis parallel to the wind direction.

\section{ACKNOWLEDGMENTS}

This study was completed under the direction of J. Wo Johnson. The author expresses his appreciation to him and to R. L. Wiegel for many helpful suggestions and for critical reading of the manuscript. He is also obliged to $J$. Kukk for his help in reducing the data, to $M$. M. Lincoln for the 1 llstrations and E. Henderson for typing the manuscript. 
多 $h=$ Set-up of leeword shore, in feet

7 F = Fetch, in feet

$5=$ Wind velocity, in feet/second

$q$ = Acceleration of grovity, in feet/second ${ }^{2}$

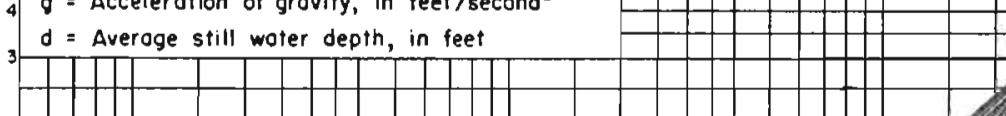

$\omega$

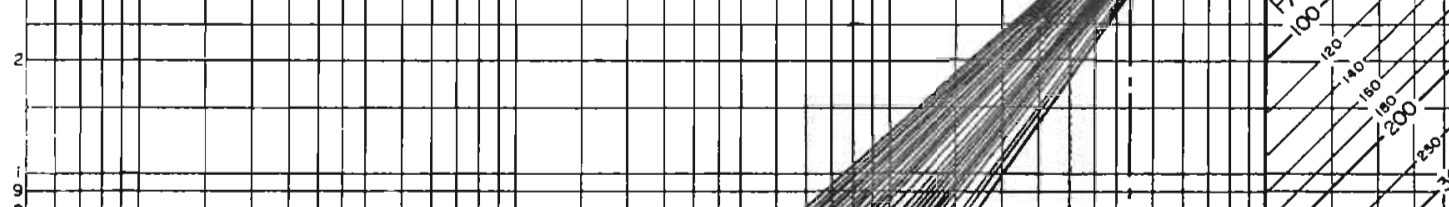

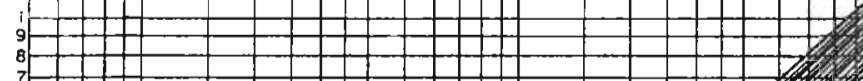

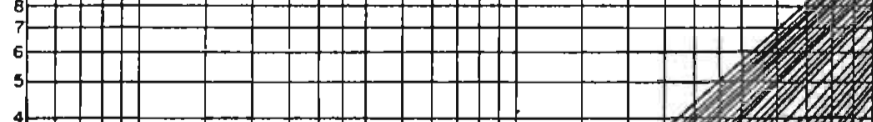

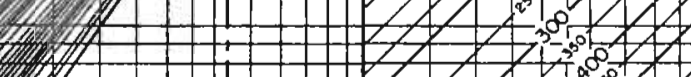

IIII-1
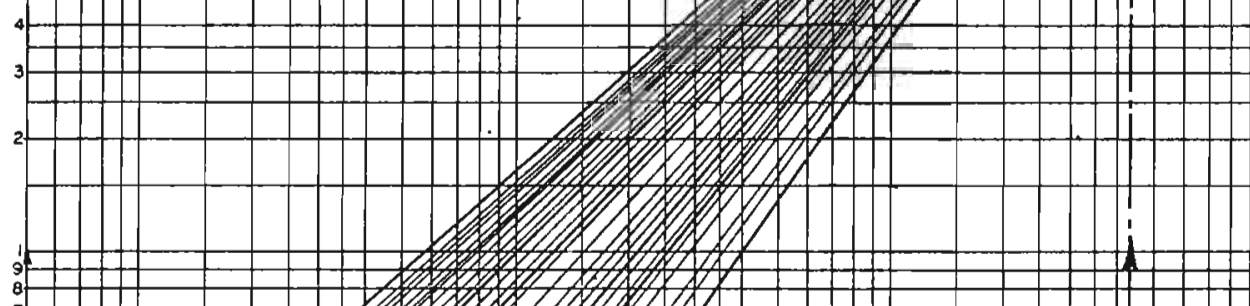

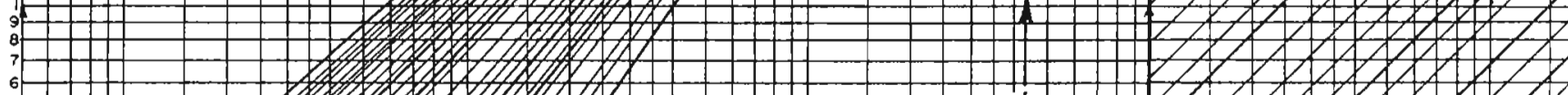

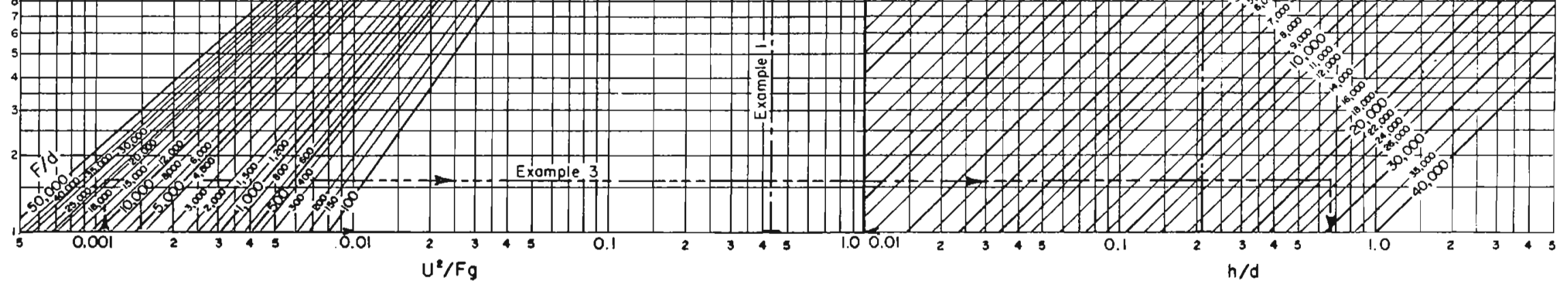

FIGURE 25-0 - NOMOGRAM FOR THE DETERMINATION OF WIND TIDES

PART I 


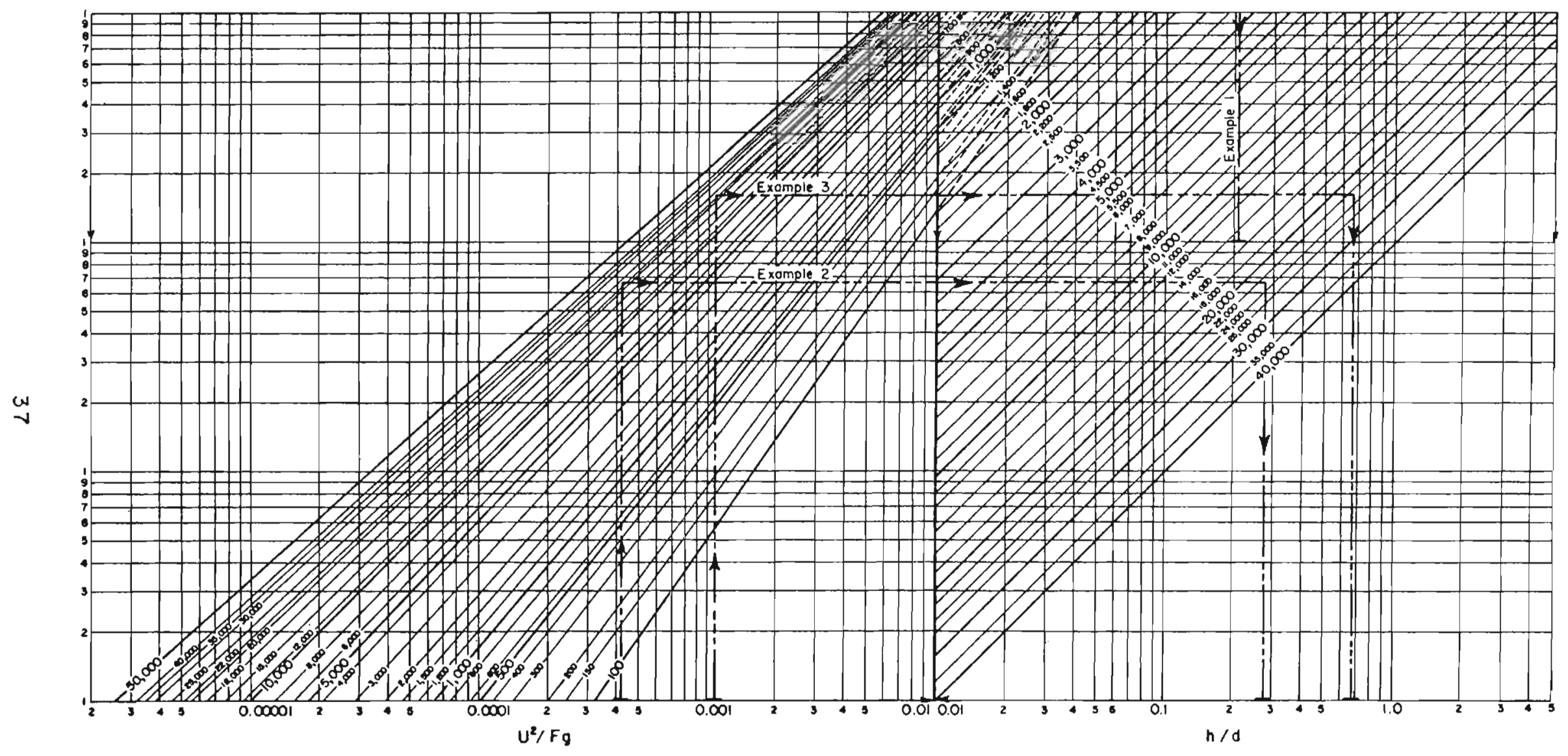

FIGURE 25-b - NOMOGRAM FOR THE DETERMINATION OF WIND TIDES PART II 


\section{REFERENCES}

1. Palmen, E. Uber die von einem stationaren Wind verursachte Wasserstauung Bericht 15B, Hydrol. Konferenz der Baltischen Staaten, Finnland, 1936.

2. Palmen, E. and Laurila, E. Uber die Einwirkung eines Sturmes auf den hydrograph. Zunstand im nordlichen Ostseegebiet, Comment. Phys. Mat., Helsing fors, 10, No. 1, 53 pp. 1938.

3. Hellstrom, B. Wind Effect on Lakes and Rivers. Royal Swedish Inst., for Engineering Res., Proceeding No. 158, Stockholm, 1941.

4. Corps of Engineers, U. S. Army, Office of the District Enrineer, Jacksonville, Fla. Project, CW-167, Waves and Wind Tides in Inland Waters, Lake Okeechobee, Fla. Project Bulletins Nos. 2 through 7, Hurricane data for 1949, 1948, 1947, 1945, 1950 and 1952 (unpublished).

5. Langhaar, H. L. Wind Tides in Inland Waters, Proc. No. 4, first Midwestern Conf. on Fluid Mech., Ann Arbor, Mich., 1951.

6. Saville, T., Jr., Wind Set-up and Waves in Shallow Water, Tech. Memo. No. 27, Beach Erosion Board, 1952.

7. Keulegan, G. H, Wind Tides in Small Closed Channels, Jour. of Res. of National Bu. Stds., Vol. 46, No. 5, May 1951.

8. Keulegan, G. H., The Form Factor in Wind-Tide Formulas, National Bu. of Stds., Rpt. No. 1835, 1952.

9. Francis, J.R.D., The Aerodynamic Drag of a Free Water Surface, Proc. Roy. Soc. A.V. 206, pp. 387-406, London, May 1951.

10. Dorn, W. G. Van, Wind Stress Over Water, Univ, of Calif., Scripps Inst. of Oceano., La Jolla, Nov. 20, 1952.

11. Sibul, 0., Water Surface Roughness and Wind Shear Stress in a Laboratory Wind-Wave Channel, Tech. Memo. No. 74, Beach Erosion Board, 1955.

12. Ekman, V. W., On the InIluence of the Earth' Rotation on Ocean Currents, Arkiv for matematik, Astron. och fysik, Vol. 2, No. 11, Stockholm; 1905.

13. Ekman, V. W., Beitrage zur Theorie der Meeresstromungen, Annalen der Hydrographie und Maritimen Meteorologie, H.9-12, Berlin, 1906. 
14. Hidaka, Koji, Wind Driven Sea Level Change of a Shallow Sea Over a Continential Shelf, The A \& M College of Texas, Dept of Oceano., Tech. Rpt. No. 9, Oct 1953.

15. Forel, F. A., Le Leman, I-III, Lausanne, 1892-1904, Study of Selches and Wind Tides on Lake Geneva.

16. Boussinesq, J. Essai sur la theorie des eaux courantes, Memoires presentes par divers savants a l'Academie des Sciences de l'Institut National de France, Tome XXIII, No. 1, Paris 1877.

17. Boussinesq, J., Expression du frottement exterieur dans l'ecoulement tumultueux d'un fluide, Comptes Rendus des seances de l'Academie des Sciences, 22 Juin 1896, Paris, 1896.

18. Boussinesq, J., Theorie de l'ecoulement tourbillonnant et tumultueux des liquides dans les lits rectilignes a grandes sections, Deux Memoires, Paris 1897.

19. Corps of Engineers, U. S. Army, Office of the District Engineer, Jacksonville, Fla., Central and Southern Florida Project for Flood Control and Other Purposes, Part IV, Lake Okeechobee and Outlets, Jan. 21, 1954, unpublished.

20. Thifsse, J. Th., On Wind Effects, United States Waterways Experiment Station, Bull. Vol. No. 2, 1938.

21. Creager, W. P., Justin, J. D, and Hinds, J., Engineering For Dams, New York, 1945.

22. Hellstrom, B., Wind Effect on Ringskobing Fford, Am. Geoph. Union, Vol. 34, No. 2, April 1953. 
TABLE I - SUMMARY OF DATA

\begin{tabular}{|c|c|c|c|c|c|c|c|c|c|c|c|c|}
\hline $\begin{array}{l}\dot{0} \\
z \\
z \\
0\end{array}$ & 容 & 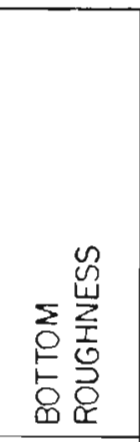 & 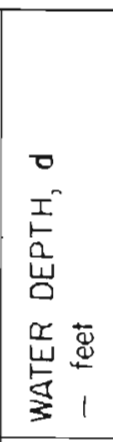 & 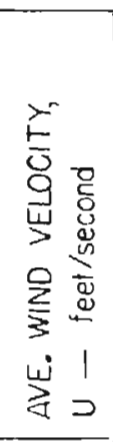 & 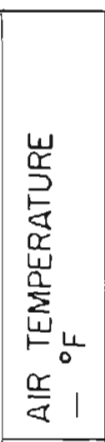 & 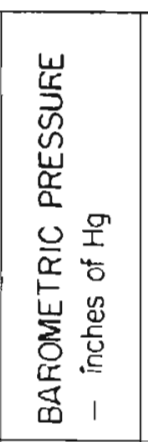 & 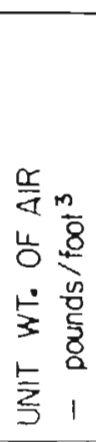 & 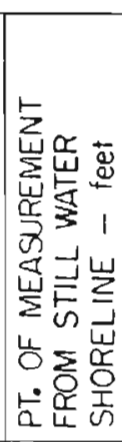 & 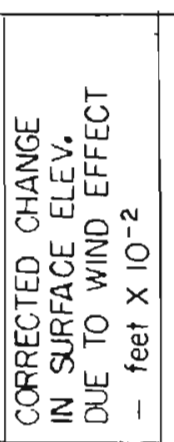 & 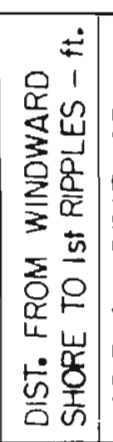 & 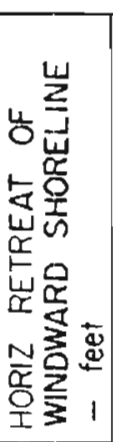 & 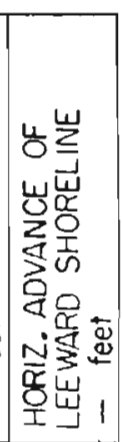 \\
\hline 1 & 2 & 3 & 4 & 5 & 6 & 7 & 8 & 9 & 10 & 11 & 12 & 13 \\
\hline $1-$ & 1953 & & & & 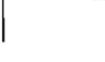 & | 1 & & & & & & \\
\hline 5 & $\begin{array}{l}\text { Nov. } \\
2\end{array}$ & These $\mathrm{r}$ & uns wer & made & to study & $y$ the char & acterist & ics of the & channel; n & no woter & If iivolve & \\
\hline 6 & 10 & smooth & 0.096 & 23.0 & 57 & 30.030 & & $\begin{array}{r}4.36 \\
14.37 \\
24.38 \\
34.38 \\
44.38\end{array}$ & $\begin{array}{l}-1.48 \\
-0.49 \\
0.187 \\
0.74 \\
1.22\end{array}$ & & & \\
\hline 7 & 11 & smooth & 0.10 & 13.7 & 63.5 & 30.132 & & $\begin{array}{r}4.46 \\
11.47 \\
24.48 \\
34.48 \\
44.48\end{array}$ & $\begin{array}{r}-0.427 \\
-0.194 \\
0.016 \\
0.292 \\
0.331\end{array}$ & & & \\
\hline 8 & 12 & smooth & 0.0985 & 9.80 & 62 & 30.084 & & $\begin{array}{l}4.46 \\
14.47 \\
24.48 \\
34.48 \\
44.48\end{array}$ & $\mid \begin{array}{c}-0.254 \\
-0.122 \\
-0.0098 \\
0.115 \\
0.220\end{array}$ & & & \\
\hline 9 & $\begin{array}{c}\text { Dec. } \\
22\end{array}$ & smooth & 0.072 & 34.5 & 54 & 30.408 & & $\begin{array}{r}4.26 \\
14.27 \\
24.28 \\
34.28 \\
44.28\end{array}$ & $\begin{array}{l}\text { botiom } \\
\text { exposed } \\
-1.43 \\
-0.97 \\
2.41 \\
3.52\end{array}$ & & & \\
\hline 10 & 23 & smooth & 0.068 & 33.8 & 60 & 30.593 & & $\begin{array}{r}4.25 \\
14.26 \\
24.27 \\
34.27 \\
44.27\end{array}$ & $\begin{array}{c}-- \\
-1.22 \\
0.85 \\
2.26 \\
3.31\end{array}$ & & & \\
\hline 11 & & smooth & 0.060 & 37.0 & 58 & 30.594 & & $\begin{array}{r}4.24 \\
14.25 \\
24.26 \\
34.26 \\
44.26\end{array}$ & \begin{tabular}{|} 
bi'm expos'd \\
0.872 \\
3.179 \\
5.347
\end{tabular} & & & \\
\hline
\end{tabular}


Table I (cont.)

\begin{tabular}{|c|c|c|c|c|c|c|c|c|c|c|c|c|}
\hline 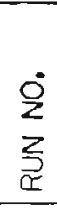 & 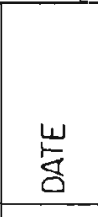 & 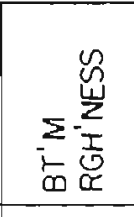 & 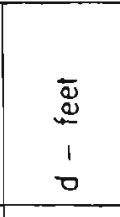 & 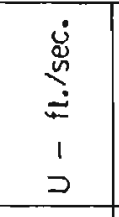 & 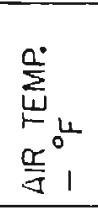 & 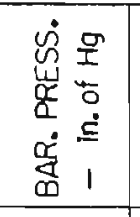 & 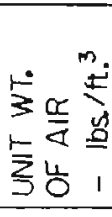 & 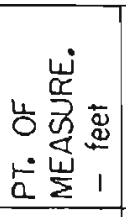 & 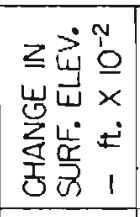 & 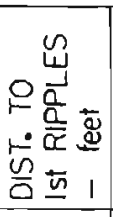 & 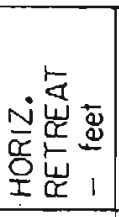 & 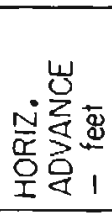 \\
\hline 1 & 2 & 3 & 4 & 5 & 6 & 7 & 8 & 9 & 10 & 11 & 12 & 13 \\
\hline 12 & $\begin{array}{c}1954 \\
\text { Jan. } \\
14\end{array}$ & smooth & 0.370 & 10.05 & 55 & 30.150 & & $\begin{array}{r}7.01 \\
17.02 \\
27.03 \\
37.03 \\
47.03\end{array}$ & $\begin{array}{r}-0.140 \\
-0.065 \\
0.098 \\
0.040 \\
0.106\end{array}$ & & & \\
\hline 13 & 15 & smooth & 0.368 & 14.10 & 52.5 & 30.206 & & $\begin{array}{r}7.18 \\
17.19 \\
27.20 \\
37.20 \\
47.20\end{array}$ & $\begin{array}{r}-0.156 \\
-0.047 \\
0.028 \\
0.038 \\
0.104\end{array}$ & & & \\
\hline 14 & & smooth & 0.367 & 19.25 & 52.5 & 30.206 & & $\begin{array}{r}7.21 \\
17.22 \\
27.23 \\
37.23 \\
47.23\end{array}$ & $\begin{array}{r}-0.251 \\
-0.113 \\
0.028 \\
0.280 \\
0.543\end{array}$ & & & \\
\hline 15 & & smooth & 0.365 & 25.6 & 52.5 & 30.206 & & $\begin{array}{r}7.21 \\
17.22 \\
27.23 \\
37.23 \\
47.23\end{array}$ & $\begin{array}{r}-0.755 \\
-0.374 \\
0.075 \\
0.500 \\
1.200\end{array}$ & & & \\
\hline 16 & 18 & smooth & 0.367 & 33.4 & 48.4 & 29.970 & & $\begin{array}{r}7.13 \\
17.14 \\
27.15 \\
37.15 \\
47.15\end{array}$ & $\begin{array}{r}-2.56 \\
-1.18 \\
0.25 \\
1.03 \\
2.43\end{array}$ & & & \\
\hline 17 & 20 & smooth & 0.300 & 33.0 & 53.0 & 30.012 & & $\begin{array}{r}6.46 \\
16.47 \\
26.48 \\
36.48 \\
46.48\end{array}$ & $\begin{array}{l}-1.89 \\
-1.39 \\
0.030 \\
0.780 \\
1.83\end{array}$ & & & \\
\hline 18 & & smooth & 0.301 & 25.2 & 53.0 & 30.012 & & $\begin{array}{r}6.34 \\
16.35 \\
26.36 \\
36.36 \\
46.36\end{array}$ & $\begin{array}{r}-0.89 \\
-0.45 \\
0.05 \\
0.51 \\
0.85\end{array}$ & & & \\
\hline 19 & 21 & smooth & 0.300 & 20.3 & 48.0 & 30.334 & & $\begin{array}{r}6.39 \\
16.40 \\
26.41 \\
36.42 \\
46.42\end{array}$ & $\begin{array}{r}-0.54 \\
-0.28 \\
+0.00 \\
-0.30 \\
0.54\end{array}$ & & & \\
\hline
\end{tabular}




\begin{tabular}{|c|c|c|c|c|c|c|c|c|c|c|c|c|}
\hline I & 2 & 3 & 4 & 5 & 6 & 7 & 8 & 9 & 10 & 11 & 12 & 13 \\
\hline 20 & 21 & smooth & 0.301 & 16.30 & 48 & 30.334 & & $\begin{array}{r}6.36 \\
16.37 \\
26.38 \\
36.38 \\
46.38\end{array}$ & $\begin{array}{r}-0.26 \\
-0.11 \\
0.03 \\
0.16 \\
0.26\end{array}$ & & & \\
\hline 21 & 22 & smooth & 0.301 & 11.20 & 48 & 30.050 & & $\begin{array}{r}6.39 \\
16.40 \\
26.41 \\
36.42 \\
46.42\end{array}$ & $\begin{array}{r}-0.09 \\
-0.03 \\
0.02 \\
0.04 \\
0.09\end{array}$ & $7.0 r$ & 0.03 & 0.08 \\
\hline 22 & 25 & smooth & 0.251 & 31.2 & 52.5 & 30.174 & & $\begin{array}{r}5.81 \\
15.82 \\
25.83 \\
35.83 \\
45.83\end{array}$ & $\begin{array}{r}-2.354 \\
-1.190 \\
-0.067 \\
1.094 \\
2.124\end{array}$ & 0.80 & 0.45 & 1.30 \\
\hline 23 & & smooth & 0.251 & 25.0 & 52.5 & 30.174 & & $\begin{array}{l}5.89 \\
15.90 \\
25.91 \\
35.91 \\
45.91\end{array}$ & $\begin{array}{r}-1.011 \\
-0.532 \\
-0.082 \\
0.515 \\
0.907\end{array}$ & 1.50 & 0.23 & 0.70 \\
\hline 24 & 26 & smooth & 0.251 & 20.4 & 50.0 & 30.318 & & $\begin{array}{r}5.81 \\
15.82 \\
25.83 \\
35.83 \\
45.83\end{array}$ & $\begin{array}{r}-0.639 \\
-0.334 \\
-0.068 \\
0.150 \\
0.611\end{array}$ & 2.35 & 0.13 & 0.46 \\
\hline 25 & $\begin{array}{c}\text { Feb. } \\
15\end{array}$ & smooth & 0.250 & 15.2 & 53.5 & 30.260 & & $\begin{array}{r}5.84 \\
15.85 \\
25.86 \\
35.86 \\
45.86\end{array}$ & $\begin{array}{r}-0.321 \\
-0.138 \\
-0.010 \\
0.138 \\
0.240\end{array}$ & 3.60 & 0.48 & 0.16 \\
\hline 26 & 16 & smooth & 0.251 & 11.1 & 48.3 & 30.068 & & $\begin{array}{r}5.73 \\
15.74 \\
25.75 \\
35.75 \\
45.75\end{array}$ & $\begin{array}{l}-0.141 \\
-0.062 \\
-0.00 \\
-0.039 \\
0.141\end{array}$ & 6.40 & - & - \\
\hline 27 & & smooth & 0.200 & 10.7 & 48.3 & 30.068 & 0.0771 & $\begin{array}{l}5.39 \\
15.40 \\
25.41 \\
35.41 \\
45.41\end{array}$ & $\begin{array}{r}-0.203 \\
0.009 \\
0.039 \\
0.157 \\
0.229\end{array}$ & 6.50 & 0.08 & 0.05 \\
\hline 28 & 18 & smooth & 0.200 & 15.80 & 57 & 30.492 & 0.0780 & $\begin{array}{r}5.36 \\
15.37 \\
25.38 \\
35.38 \\
45.38\end{array}$ & $\begin{array}{r}-0.364 \\
-0.151 \\
-0.036 \\
0.112 \\
0.410\end{array}$ & 3.50 & 0.02 & 0.14 \\
\hline
\end{tabular}


Table I (cont.)

\begin{tabular}{|c|c|c|c|c|c|c|c|c|c|c|c|c|}
\hline \begin{tabular}{l}
$\dot{0}$ \\
$z$ \\
\multirow{2}{2}{}
\end{tabular} & 㟥 & 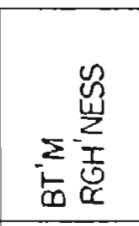 & $\begin{array}{l}\bar{\Phi} \\
1 \\
0\end{array}$ & 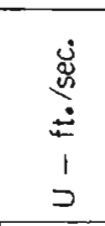 & 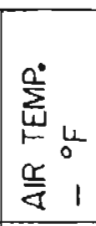 & 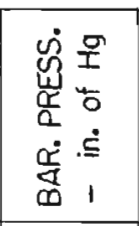 & 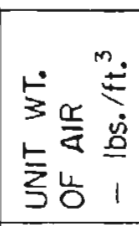 & 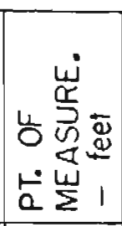 & 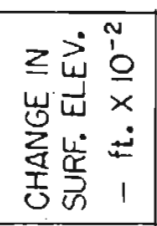 & 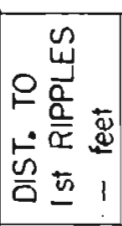 & 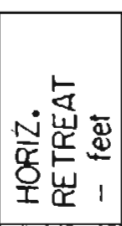 & 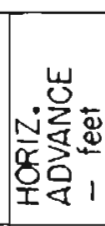 \\
\hline 1 & 2 & 3 & 4 & 5 & 6 & 7 & 8 & 9 & 10 & 11 & 12 & 13 \\
\hline 29 & $\left|\begin{array}{c}1954 \\
F e b . \\
18\end{array}\right|$ & smooth & 0.200 & 20.0 & 57 & 30.492 & 0.0784 & $\begin{array}{r}5.36 \\
15.37 \\
25.38 \\
35.38 \\
45.38\end{array}$ & $\begin{array}{l}-0.787 \\
-0.426 \\
-0.0426 \\
0.312 \\
0.705\end{array}$ & 2.25 & 0.17 & 0.22 \\
\hline 30 & 19 & smooth & 0.201 & 24.3 & 62.4 & 30.510 & 0.0784 & $\begin{array}{r}5.35 \\
15.36 \\
25.37 \\
35.37 \\
45.37\end{array}$ & $\begin{array}{r}-1.145 \\
-0.568 \\
0.039 \\
0.604 \\
1.037\end{array}$ & 1.15 & 0.22 & 0.42 \\
\hline 31 & 23 & smooth & 0.202 & 30.5 & 68.2 & 30.326 & 0.0754 & $\begin{array}{r}5.38 \\
15.39 \\
25.40 \\
35.40 \\
45.40\end{array}$ & $\begin{array}{l}-2.45 \\
-1.238 \\
-0.112 \\
1.187 \\
2.203\end{array}$ & - & -- & - \\
\hline 32 & 25 & smooth & 0.153 & 28.7 & 74.0 & 30.128 & 0.0753 & $\begin{array}{r}4.91 \\
14.92 \\
24.93 \\
34.93 \\
44.93\end{array}$ & $\begin{array}{r}-3.045 \\
-1.391 \\
0.187 \\
1.565 \\
2.736\end{array}$ & 0.65 & 0.65 & 1.00 \\
\hline 33 & & smooth & 0.152 & 24.0 & 74.0 & 30.128 & 0.0745 & $\begin{array}{r}4.83 \\
4.84 \\
24.85 \\
34.85 \\
44.85\end{array}$ & $\begin{array}{r}-1.453 \\
-0.646 \\
0.105 \\
0.781 \\
1.401\end{array}$ & 0.90 & 0.22 & 0.55 \\
\hline 34 & 26 & smooth & 0.151 & 20.5 & 69.8 & 30.084 & 0.0766 & $\begin{array}{r}4.78 \\
14.79 \\
24.80 \\
34.80 \\
44.80\end{array}$ & $\begin{array}{r}-0.906 \\
-0.433 \\
0.056 \\
0.512 \\
0.892\end{array}$ & 2.80 & 0.09 & 0.27 \\
\hline 35 & & smooth & 0.151 & 15.5 & 69.8 & 30.084 & 0.0751 & $\begin{array}{r}4.78 \\
14.79 \\
24.80 \\
34.80 \\
44.80\end{array}$ & $\begin{array}{r}-0.518 \\
-0.312 \\
-0.008 \\
0.210 \\
0.443\end{array}$ & 3.70 & 0.02 & 0.22 \\
\hline 36 & & smooth & 0.151 & 10.9 & 69.8 & 30.084 & 0.0750 & $\begin{array}{l}4.80 \\
14.81 \\
24.82 \\
34.82 \\
44.82\end{array}$ & $\begin{array}{r}-0.217 \\
-0.135 \\
-0.043 \\
0.069 \\
0.174\end{array}$ & 5.40 & 0.02 & 0.07 \\
\hline
\end{tabular}




\begin{tabular}{|c|c|c|c|c|c|c|c|c|c|c|c|c|}
\hline 1 & 2 & 3 & 4 & 5 & 6 & 7 & 8 & 9 & 10 & 11 & 12 & 13 \\
\hline 37 & $\begin{array}{c}\text { Mar. } \\
1\end{array}$ & smooth & 0.101 & 31.5 & 68.3 & 29.926 & 0.0747 & $\begin{array}{r}4 \cdot 32 \\
14 \cdot 33 \\
24 \cdot 34 \\
34 \cdot 34 \\
44 \cdot 34\end{array}$ & $\begin{array}{r}-5.384 \\
-1.788 \\
0.722 \\
2.717 \\
4.606\end{array}$ & 0.50 & 2.56 & 1.45 \\
\hline 38 & & smooth & 0.101 & 24.4 & 68.3 & 29.926 & 0.0742 & $\begin{array}{r}4.23 \\
14.24 \\
24.25 \\
34.25 \\
44.25\end{array}$ & $\begin{array}{r}-2.113 \\
-0.846 \\
0.203 \\
1.132 \\
1.890\end{array}$ & 1.00 & 0.22 & 0.43 \\
\hline 39 & 2 & smooth & 0.101 & 20.4 & 69.8 & 29.948 & 0.0757 & $\begin{array}{r}4.25 \\
14.26 \\
24.27 \\
34.27 \\
44.27\end{array}$ & $\begin{array}{r}-1.246 \\
-0.521 \\
0.124 \\
0.715 \\
1.207\end{array}$ & 1.90 & 0.13 & 0.27 \\
\hline 40 & & smooth & 0.101 & 15.8 & 69.8 & 29.948 & 0.0753 & $\begin{array}{r}4.28 \\
4.29 \\
24.30 \\
34.30 \\
44.30\end{array}$ & $\begin{array}{r}-0.751 \\
-0.318 \\
0.059 \\
0.377 \\
0.696\end{array}$ & 4.0 & 0.02 & 0.18 \\
\hline 41 & & smooth & 0.101 & 11.4 & 69.8 & 29.948 & 0.0751 & $\begin{array}{r}4.25 \\
14.26 \\
24.27 \\
34.27 \\
44.27\end{array}$ & $\begin{array}{r}-0.299 \\
-0.157 \\
0.033 \\
0.131 \\
0.295\end{array}$ & 6.8 & 0.01 & 0.03 \\
\hline 42 & 3 & smooth & 0.051 & 30.3 & 52.3 & 30.072 & 0.0771 & $\begin{array}{r}3.86 \\
13.87 \\
23.88 \\
33.88 \\
43.88\end{array}$ & $\begin{array}{l}\text { bottom } \\
\text { exposed } \\
0.548 \\
3.278 \\
5.367\end{array}$ & 0.40 & 17.00 & 1.02 \\
\hline 43 & & smooth & 0.051 & 23.9 & 52.3 & 30.072 & 0.0772 & $\begin{array}{r}3.79 \\
13.80 \\
23.81 \\
33.81 \\
43.81\end{array}$ & $\begin{array}{r}\text { bottom } \\
\text { exposed } \\
-1.253 \\
0.709 \\
2.136 \\
3.150\end{array}$ & 1.20 & 7.63 & 0.47 \\
\hline 44 & & smooth & 0.051 & 19.9 & 52.3 & 30.072 & 0.0768 & $\begin{array}{r}3.81 \\
13.82 \\
23.83 \\
33.83 \\
43.83\end{array}$ & $\begin{array}{r}-2.546 \\
-0.787 \\
0.417 \\
1.401 \\
2.175\end{array}$ & 2.40 & 2.15 & 0.37 \\
\hline 45 & 4 & smooth & 0.051 & 16.0 & 51.5 & 30.248 & 0.0780 & $\begin{array}{r}3.81 \\
13.82 \\
23.83 \\
33.83 \\
43.83\end{array}$ & $\begin{array}{r}-1.207 \\
-0.436 \\
0.220 \\
0.804 \\
1.335\end{array}$ & 5.00 & 0.16 & 0.18 \\
\hline
\end{tabular}


Table I (cont.)

\begin{tabular}{|c|c|c|c|c|c|c|c|c|c|c|c|c|}
\hline $\begin{array}{l}\dot{0} \\
\vdots \\
\grave{\partial}\end{array}$ & $\begin{array}{l}\text { 岁 } \\
\frac{7}{0}\end{array}$ & 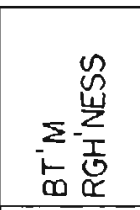 & $\begin{array}{l}\bar{a} \\
\mathbb{a} \\
1 \\
1 \\
0\end{array}$ & 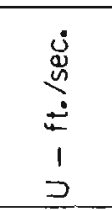 & 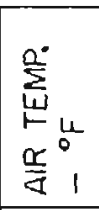 & 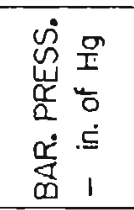 & 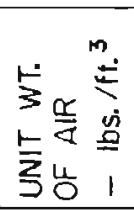 & 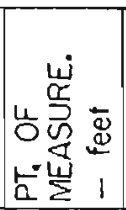 & 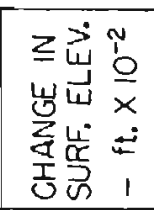 & 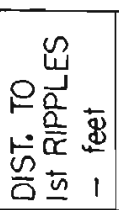 & 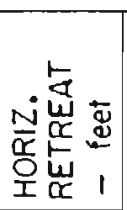 & 岁 \\
\hline 1 & 2 & 3 & 4 & 5 & 6 & 7 & 8 & 9 & 10 & 11 & 12 & 13 \\
\hline 46 & $\begin{array}{c}1954 \\
\text { Mar. } \\
4\end{array}$ & smooth & 0.051 & 21.2 & 51.5 & 30.248 & 0.0778 & $\begin{array}{r}3.80 \\
13.81 \\
23.82 \\
33.82 \\
43.82\end{array}$ & $\begin{array}{r}-0.584 \\
-0.223 \\
0.108 \\
0.394 \\
0.577\end{array}$ & 12.5 & 0.06 & 0.03 \\
\hline 47 & $\begin{array}{l}\text { Apr. } \\
15\end{array}$ & smooth & 0.073 & 12.25 & 68.0 & 30.202 & 0.0755 & $\begin{array}{r}4.08 \\
14.09 \\
24.10 \\
34.10 \\
44.10\end{array}$ & $\begin{array}{r}-0.37 \\
-0.17 \\
0.03 \\
0.10 \\
0.36\end{array}$ & 5.7 & 0.04 & 0.08 \\
\hline 48 & & smooth & 0.073 & 17.25 & 74.0 & 30.202 & 0.0747 & $\begin{array}{r}4.08 \\
14.09 \\
24.10 \\
34.10 \\
44.10\end{array}$ & $\begin{array}{r}-0.95 \\
-0.46 \\
0.03 \\
0.47 \\
0.95\end{array}$ & 3.75 & 0.11 & 0.25 \\
\hline 49 & & smooth & 0.074 & 21.95 & 71.0 & 30.202 & 0.0750 & $\begin{array}{r}4.08 \\
14.09 \\
24.10 \\
34.10 \\
44.10\end{array}$ & $\begin{array}{r}-1.79 \\
-0.81 \\
0.04 \\
0.70 \\
1.53\end{array}$ & 1.70 & 0.26 & 0.36 \\
\hline 50 & & smooth & 0.074 & 25.80 & 71.0 & 30.202 & 0.0750 & $\begin{array}{r}4.08 \\
14.09 \\
24.10 \\
34.10 \\
44.10\end{array}$ & $\begin{array}{r}-2.93 \\
-1.19 \\
0.15 \\
0.86 \\
2.31\end{array}$ & - & 0.43 & 0.52 \\
\hline 51 & 16 & smooth & 0.073 & 32.65 & 69.0 & 30.342 & 0.0753 & $\begin{array}{r}4.08 \\
4.09 \\
24.10 \\
34.10 \\
44.10\end{array}$ & $\begin{array}{c}\text { bottom } \\
\text { exposed } \\
-2.20 \\
0.84 \\
3.21 \\
5.25\end{array}$ & 0.20 & 8.93 & 1.25 \\
\hline 52 & 19 & rough & 0.073 & 11.80 & 65.0 & 30.048 & 0.0756 & $\begin{array}{r}4.01 \\
14.02 \\
24.03 \\
34.03 \\
44.03\end{array}$ & $\begin{array}{r}-0.52 \\
-0.22 \\
0.03 \\
0.31 \\
0.49\end{array}$ & 6.0 & 0.04 & 0.05 \\
\hline 53 & 20 & rough & 0.074 & 16.85 & 59.0 & 30.118 & 0.0767 & $\begin{array}{r}4.07 \\
14.08 \\
24.09 \\
34.09 \\
44.09\end{array}$ & $\begin{array}{r}-1.06 \\
-0.53 \\
0.10 \\
0.56 \\
0.97\end{array}$ & 4.50 & 0.12 & 0.16 \\
\hline
\end{tabular}




\begin{tabular}{|c|c|c|c|c|c|c|c|c|c|c|c|c|}
\hline 1 & 2 & 3 & 4 & 5 & 6 & 7 & 8 & 9 & 10 & 11 & 12 & 13 \\
\hline 54 & Apr. & rough & 0.074 & 21.15 & 63.0 & 30.118 & 0.0761 & $\begin{array}{r}4.04 \\
14.05 \\
24.06 \\
34.06 \\
44.06\end{array}$ & $\begin{array}{r}-2.02 \\
-0.86 \\
0.18 \\
0.95 \\
1.63\end{array}$ & 2.0 & 0.24 & 0.26 \\
\hline 55 & & rough & 0.074 & 25.60 & 63.0 & 30.118 & 0.0761 & $\begin{array}{r}4.00 \\
14.01 \\
24.02 \\
34.02 \\
44.02\end{array}$ & $\begin{array}{r}-3.93 \\
-1.39 \\
0.44 \\
1.73 \\
2.43\end{array}$ & 0.75 & 2.79 & 0.44 \\
\hline 56 & & rough & 0.074 & 31.80 & 63.0 & 30.118 & 0.0761 & $\begin{array}{r}4.01 \\
14.02 \\
24.03 \\
34.03 \\
44.03\end{array}$ & $\begin{array}{c}\text { bottom } \\
\text { exposed } \\
-3.22 \\
0.96 \\
3.58 \\
5.77\end{array}$ & 0.20 & 12.35 & 1.43 \\
\hline 57 & 21. & rough & 0.05 & 11.75 & 58.0 & 30.020 & 0.0765 & $\begin{array}{r}3.86 \\
13.87 \\
23.88 \\
33.88 \\
43.88\end{array}$ & $\begin{array}{r}-0.94 \\
-0.40 \\
0.02 \\
0.38 \\
0.69\end{array}$ & 10.0 & 0.16 & 0.16 \\
\hline 58 & & rough & 0.051 & 16.70 & 63.0 & 30.020 & 0.0758 & $\begin{array}{r}3.84 \\
13.85 \\
23.86 \\
33.86 \\
43.86\end{array}$ & $\begin{array}{r}-1.86 \\
-0.68 \\
0.11 \\
0.84 \\
1.44\end{array}$ & 5.20 & 1.25 & 0.18 \\
\hline 59 & & rough & 0.050 & 21.25 & 67.0 & 30.020 & 0.0752 & $\begin{array}{r}3.74 \\
13.75 \\
23.76 \\
33.76 \\
43.76\end{array}$ & $\begin{array}{c}\text { bottom } \\
\text { exposed } \\
-0.83 \\
0.67 \\
1.83 \\
2.71\end{array}$ & 2.0 & 6.88 & 0.33 \\
\hline 60 & & rough & 0.051 & 25.50 & 64.0 & 30.020 & 0.0752 & $\begin{array}{r}3.75 \\
13.76 \\
23.77 \\
33.77 \\
43.77\end{array}$ & $\begin{array}{c}\text { bottom } \\
\text { exposed } \\
-2.49 \\
0.48 \\
2.24 \\
4.51\end{array}$ & 1.0 & 12.79 & 0.44 \\
\hline 61 & & rough & 0.051 & 32.35 & 64.0 & 30.020 & 0.0756 & $\begin{array}{r}3.79 \\
13.80 \\
23.81 \\
33.81 \\
43.81\end{array}$ & $\begin{array}{c}\text { botlom } \\
\text { exposed } \\
0.28 \\
3.70 \\
5.70\end{array}$ & -- & 20.33 & 0.94 \\
\hline 62 & 22 & rough & 0.099 & 11.45 & 56.0 & 29.940 & 0.0766 & $\begin{array}{r}4 \cdot 34 \\
14 \cdot 35 \\
24 \cdot 36 \\
34 \cdot 36 \\
44 \cdot 36\end{array}$ & $\begin{array}{r}-0.35 \\
-0.20 \\
-0.02 \\
0.19 \\
0.32\end{array}$ & -- & 0.01 & 0.02 \\
\hline
\end{tabular}


Table I (cont.)

\begin{tabular}{|c|c|c|c|c|c|c|c|c|c|c|c|c|}
\hline $\begin{array}{l}\dot{0} \\
\sum_{3} \\
\dot{u}\end{array}$ & $\begin{array}{l}\text { 岁 } \\
\end{array}$ & 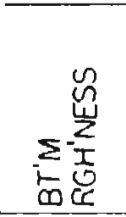 & $\begin{array}{l}\frac{\bar{\Phi}}{\Phi} \\
1 \\
0\end{array}$ & 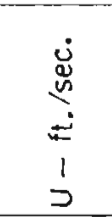 & 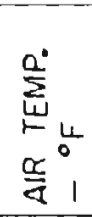 & 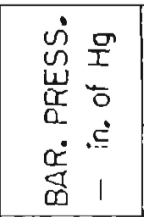 & 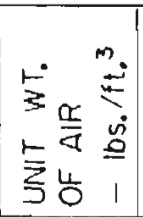 & 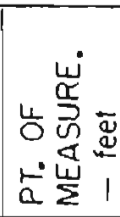 & 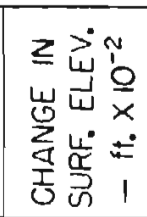 & 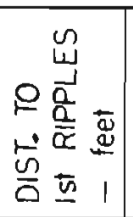 & 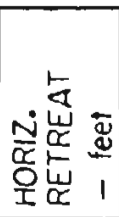 & 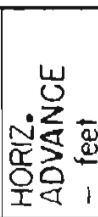 \\
\hline 1 & 2 & 3 & 4 & 5 & 6 & 7 & 8 & 9 & 10 & II & 12 & 13 \\
\hline 63 & $\begin{array}{c}1954 \\
\text { Apr. } \\
22\end{array}$ & rough & 0.099 & 16.50 & 61.0 & 29.940 & 0.0758 & $\begin{array}{l}4 \cdot 32 \\
4.33 \\
24 \cdot 34 \\
34 \cdot 34 \\
44 \cdot 34\end{array}$ & $\begin{array}{r}-0.77 \\
-0.45 \\
0.03 \\
0.40 \\
0.75\end{array}$ & 4.30 & 0.07 & 0.17 \\
\hline 64 & & rough. & 0.099 & 21.10 & 63.0 & 29.940 & 0.0756 & $\begin{array}{r}4.32 \\
14 \cdot 33 \\
24 \cdot 34 \\
34 \cdot 34 \\
44 \cdot 34\end{array}$ & $\begin{array}{l}-1.51 \\
-0.68 \\
+0.00 \\
0.75 \\
1.35\end{array}$ & 2.20 & 0.22 & 0.27 \\
\hline 65 & & rough & 0.099 & 25.55 & 62.0 & 29.940 & 0.0757 & $\begin{array}{r}4.28 \\
14.29 \\
24.30 \\
34.30 \\
44.30\end{array}$ & $\begin{array}{r}-2.62 \\
-1.06 \\
0.17 \\
1.23 \\
2.11\end{array}$ & 0.95 & 0.32 & 0.43 \\
\hline 66 & & rough & 0.099 & 32.40 & 62.0 & 29.940 & 0.0757 & $\begin{array}{r}4.28 \\
4.29 \\
24.30 \\
34.30 \\
44.30\end{array}$ & $\begin{array}{l}\text { boltom } \\
\text { exposed } \\
-1.61 \\
1.15 \\
3.31 \\
5.41\end{array}$ & 0.10 & 5.32 & 1.65 \\
\hline 67 & 23 & rough & 0.201 & 11.50 & 61.0 & 29.956 & 0.0759 & $\begin{array}{r}5.32 \\
15.33 \\
25.34 \\
35.34 \\
45.34\end{array}$ & $\begin{array}{r}-0.28 \\
-0.08 \\
0.03 \\
0.08 \\
0.18\end{array}$ & 5.80 & 0.01 & 0.07 \\
\hline 68 & 26 & rough & 0.202 & 16.80 & 60.0 & 30.102 & 0.0766 & $\begin{array}{r}5.33 \\
15.34 \\
25.35 \\
35.35 \\
45.35\end{array}$ & $\begin{array}{l}-0.42 \\
-0.23 \\
\pm 0.00 \\
0.22 \\
0.46\end{array}$ & 4.0 & 0.04 & 0.19 \\
\hline 69 & & rough & 0.202 & 21.05 & 63.0 & 30.102 & 0.0761 & $\begin{array}{r}5.34 \\
15.35 \\
25.36 \\
35.36 \\
45.36\end{array}$ & $\begin{array}{r}-0.76 \\
-0.38 \\
+0.00 \\
-0.35 \\
0.77\end{array}$ & 2.0 & 0.13 & 0.29 \\
\hline 70 & & rough & 0.201 & 25.70 & 65.0 & 30.102 & 0.0757 & $\begin{array}{l}5.34 \\
15.35 \\
25.36 \\
35.36 \\
45.36\end{array}$ & $\begin{array}{r}-1.33 \\
-0.64 \\
-0.01 \\
0.63 \\
1.18\end{array}$ & 1.20 & 0.22 & 0.46 \\
\hline
\end{tabular}




\begin{tabular}{|c|c|c|c|c|c|c|c|c|c|c|c|c|}
\hline I & 2 & 3 & 4 & 5 & 6 & 7 & 8 & 9 & 10 & 11 & 12 & 13 \\
\hline 71 & Apr. & rough & 0.201 & 32.50 & 67.0 & 30.102 & 0.0754 & $\begin{array}{r}5.32 \\
15.33 \\
25.34 \\
35.34 \\
45.34\end{array}$ & $\begin{array}{r}-2.72 \\
-1.43 \\
-0.25 \\
1.17 \\
2.59\end{array}$ & - & 0.49 & - \\
\hline 72 & 27 & rough & 0.372 & 11.70 & 57.0 & 29.876 & 0.0763 & $\begin{array}{r}7.21 \\
17.22 \\
27.23 \\
37.23 \\
47.23\end{array}$ & $\begin{array}{r}-0.10 \\
-0.08 \\
-0.04 \\
-0.01 \\
0.07\end{array}$ & 5.0 & 0.08 & 0.17 \\
\hline 73 & & rough & 0.372 & 16.55 & 57.5 & 29.876 & 0.0763 & $\begin{array}{r}7.14 \\
17.15 \\
27.16 \\
37.16 \\
47.16\end{array}$ & $\begin{array}{r}-0.19 \\
-0.12 \\
-0.07 \\
0.10 \\
0.20\end{array}$ & 2.50 & 0.05 & 0.21 \\
\hline 74 & 28 & rough & 0.372 & 21.25 & 58.0 & 30.070 & 0.0767 & $\begin{array}{r}7.17 \\
17.18 \\
27.19 \\
37.19 \\
47.19\end{array}$ & $\begin{array}{r}-0.41 \\
-0.25 \\
-0.06 \\
0.18 \\
0.44\end{array}$ & 2.0 & 0.16 & 0.32 \\
\hline 75 & & rough & 0.370 & 26.20 & 63.0 & 30.070 & 0.0759 & $\begin{array}{r}7.17 \\
17.18 \\
27.19 \\
37.19 \\
47.19\end{array}$ & $\begin{array}{r}-1.16 \\
-0.32 \\
0.05 \\
0.55 \\
1.07\end{array}$ & 0.85 & 0.24 & 0.69 \\
\hline 76 & & rough & 0.370 & 33.80 & $6 \% .0$ & 30.070 & 0.0753 & $\begin{array}{r}7.16 \\
17.17 \\
27.18 \\
37.18 \\
47.18\end{array}$ & $\begin{array}{r}-3.00 \\
-0.83 \\
0.10 \\
1.31 \\
2.88\end{array}$ & 0.65 & 0.65 & -- \\
\hline 77 & $\begin{array}{r}\text { May } \\
4\end{array}$ & $\begin{array}{l}\text { rough } \\
\text { with } \\
\text { weeds }\end{array}$ & 0.373 & 11.70 & 59 & 30.074 & 0.0765 & $\begin{array}{r}7.20 \\
17.21 \\
27.22 \\
37.22 \\
47.22\end{array}$ & $\begin{array}{r}-0.36 \\
-0.14 \\
0.01 \\
0.11 \\
0.25\end{array}$ & 5.00 & 0.08 & 0.07 \\
\hline 78 & & $\begin{array}{l}\text { rough } \\
\text { with } \\
\text { weeds }\end{array}$ & 0.372 & 16.80 & 59 & 30.074 & 0.0765 & $\begin{array}{r}7.20 \\
17.21 \\
27.22 \\
37.22 \\
47.22\end{array}$ & $\begin{array}{r}-0.42 \\
-0.27 \\
-0.18 \\
0.28 \\
0.42\end{array}$ & 2.70 & 0.13 & 0.36 \\
\hline 79 & 5 & $\begin{array}{l}\text { rough } \\
\text { with } \\
\text { weeds }\end{array}$ & 0.372 & 21.70 & 62 & 30.046 & 0.0760 & $\begin{array}{r}7.19 \\
17.20 \\
27.21 \\
37.21 \\
47.21\end{array}$ & $\begin{array}{r}-0.59 \\
-0.32 \\
-0.07 \\
0.25 \\
0.65\end{array}$ & 1.90 & $0.2 \mathrm{C}$ & 0.37 \\
\hline
\end{tabular}


Table I (cont.)

\begin{tabular}{|c|c|c|c|c|c|c|c|c|c|c|c|c|}
\hline $\begin{array}{l}\dot{0} \\
2 \\
z \\
\alpha \\
\end{array}$ & 崖 & 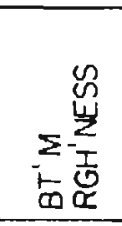 & 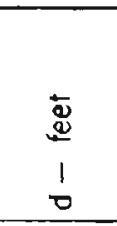 & 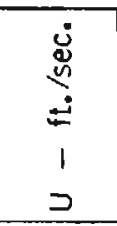 & 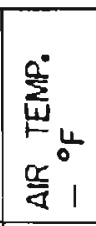 & 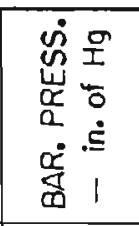 & 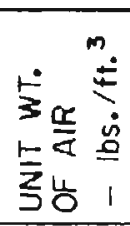 & 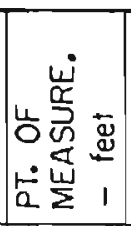 & 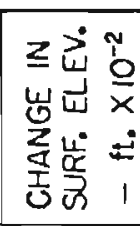 & 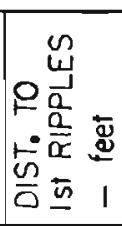 & 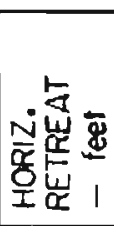 & 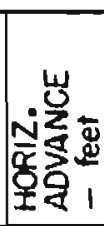 \\
\hline 1 & 2 & 3 & 4 & 5 & 6 & 7 & 8 & 9 & 10 & 11 & 12 & 13 \\
\hline 80 & $\begin{array}{c}1954 \\
\text { May } \\
5\end{array}$ & $\begin{array}{l}\text { rough } \\
\text { with } \\
\text { weeds }\end{array}$ & 0.373 & 26.30 & 67 & 30.046 & 0.0753 & $\begin{array}{r}7.18 \\
17.19 \\
27.20 \\
37.20 \\
47.20\end{array}$ & $\begin{array}{r}-0.93 \\
-0.54 \\
-0.09 \\
0.45 \\
1.01\end{array}$ & 0.85 & 0.29 & 0.77 \\
\hline 81 & & $\begin{array}{l}\text { rough } \\
\text { with } \\
\text { weeds }\end{array}$ & 0.373 & 34.0 & 67 & 30.046 & 0.0753 & $\begin{array}{r}7.19 \\
17.20 \\
27.21 \\
37.21 \\
47.21\end{array}$ & $\begin{array}{r}-2.35 \\
-1.51 \\
-0.40 \\
0.79 \\
2.42\end{array}$ & 0.60 & 0.61 & - \\
\hline 82 & & $\begin{array}{l}\text { rough } \\
\text { with } \\
\text { weeds }\end{array}$ & 0.201 & 33.40 & 70 & 30.046 & 0.0748 & $\begin{array}{r}5.40 \\
15.41 \\
25.42 \\
35.42 \\
45.42\end{array}$ & $\begin{array}{r}-3.83 \\
-1.95 \\
-0.22 \\
1.43 \\
3.26\end{array}$ & 0.65 & 0.67 & - \\
\hline 83 & 6 & $\begin{array}{l}\text { rough } \\
\text { with } \\
\text { weeds }\end{array}$ & 0.201 & 24.70 & 56 & 29.980 & 0.0768 & $\begin{array}{r}5.44 \\
15.45 \\
25.46 \\
35.46 \\
45.46\end{array}$ & $\begin{array}{c}-1.42 \\
-0.74 \\
0.03 \\
0.72 \\
1.33\end{array}$ & 1.60 & 0.31 & 0.40 \\
\hline 84 & & $\begin{array}{l}\text { rough } \\
\text { w1th } \\
\text { weeds }\end{array}$ & 0.201 & 20.20 & 60.5 & 29.980 & 0.0761 & $\begin{array}{r}5.44 \\
15.45 \\
25.46 \\
35.46 \\
45.46\end{array}$ & $\begin{array}{r}-0.76 \\
-0.39 \\
-0.10 \\
0.40 \\
0.83\end{array}$ & 2.70 & 0.18 & 0.22 \\
\hline 85 & & $\begin{array}{l}\text { rough } \\
\text { with } \\
\text { weods }\end{array}$ & 0.202 & 15.90 & 57 & 29.980 & 0.0766 & $\begin{array}{r}5.42 \\
15.43 \\
25.44 \\
35.44 \\
45.44\end{array}$ & $\begin{array}{r}-0.25 \\
-0.11 \\
-0.02 \\
0.02 \\
0.28\end{array}$ & 3.60 & 0.08 & 0.05 \\
\hline 86 & & $\begin{array}{l}\text { rough } \\
\text { w1th } \\
\text { weeds }\end{array}$ & 0.201 & 11.25 & 60 & 29.980 & 0.0761 & $\begin{array}{r}5.42 \\
15.43 \\
25.44 \\
35.44 \\
45.44\end{array}$ & $\begin{array}{r}-0.15 \\
-0.05 \\
-0.02 \\
0.07 \\
0.11\end{array}$ & 7.00 & 0.06 & 0.02 \\
\hline 87 & 7 & $\begin{array}{l}\text { rough } \\
\text { with } \\
\text { woeds }\end{array}$ & 0.101 & 12.95 & 54 & 29.944 & 0.0770 & $\begin{array}{r}4.37 \\
14.38 \\
24.39 \\
34.39 \\
44.39\end{array}$ & $\begin{array}{l}-0.23 \\
-0.11 \\
\pm 0.00 \\
0.11 \\
0.23\end{array}$ & - & 0.03 & 0.01 \\
\hline
\end{tabular}




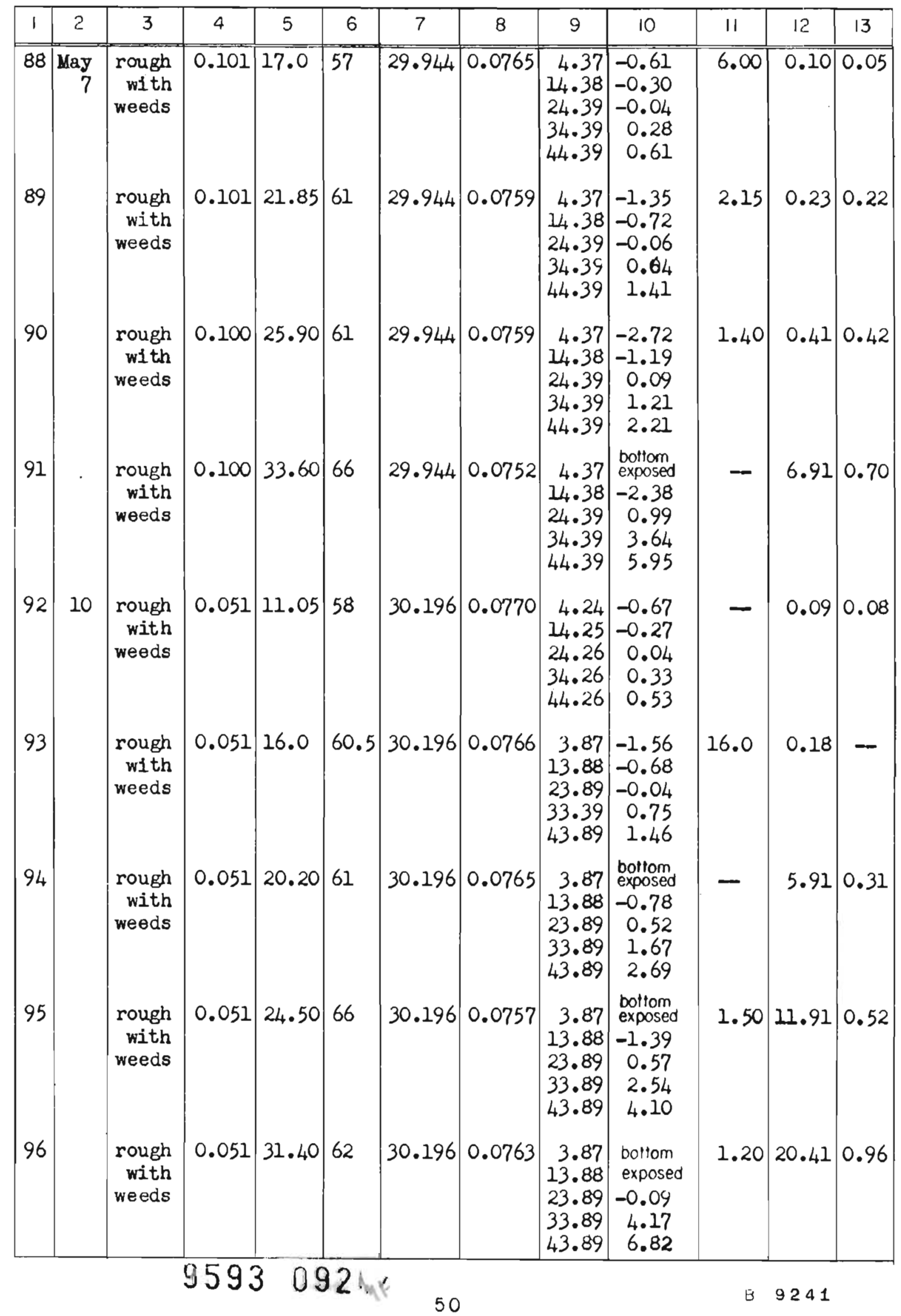

